\title{
Homologous haplotypes, expression, genetic effects and geographic distribution of the wheat yield gene TaGW2
}

Lin Qin ${ }^{1,2 \dagger}$, Chenyang Hao ${ }^{1 \dagger}$, Jian Hou' ${ }^{1}$ Y Yuquan Wang ${ }^{1}$, Tian $\mathrm{Li}^{1}$, Lanfen Wang ${ }^{1}$, Zhengqiang Ma ${ }^{2}$ and Xueyong Zhang ${ }^{1 *}$

\begin{abstract}
Background: TaGW2-6A, cloned in earlier research, strongly influences wheat grain width and TKW. Here, we mainly analyzed haplotypes of TaGW2-6B and their effects on TKW and interaction with haplotypes at TaGW2-6A.

Results: About $2.9 \mathrm{~kb}$ of the promoter sequences of TaGW2-6B and TaGW2-6D were cloned in 34 bread wheat cultivars. Eleven SNPs were detected in the promoter region of TaGW2-6B, forming 4 haplotypes, but no divergence was detected in the TaGW2-6D promoter or coding region. Three molecular markers including CAPS, dCAPS and ACAS, were developed to distinguish the TaGW2-6B haplotypes. Haplotype association analysis indicated that TaGW2-6B has a stronger influence than TaGW2-6A on TKW, and Hap-6B-1 was a favored haplotype increasing grain width and weight that had undergone strong positive selection in global wheat breeding. However, clear geographic distribution differences for TaGW2-6A haplotypes were found; Hap-6A-A was favored in Chinese, Australian and Russian cultivars, whereas Hap-6A-G was preferred in European, American and CIMMYT cultivars. This difference might be caused by a flowering and maturity time difference between the two haplotypes. Hap-6A-A is the earlier type. Haplotype interaction analysis between TaGW2-6A and TaGW2-6B showed additive effects between the favored haplotypes. Hap-6A-A/Hap-6B-1 was the best combination to increase TKW. Relative expression analysis of the three TaGW2 homoeologous genes in 22 cultivars revealed that TaGW2-6A underwent the highest expression. TaGW2-6D was the least expressed during grain development and TaGW2-6B was intermediate. Diversity of the three genes was negatively correlated with their effect on TKW.
\end{abstract}

Conclusions: Genetic effects, expression patterns and historic changes of haplotypes at three homoeologous genes of TaGW2 influencing yield were dissected in wheat cultivars. Strong and constant selection to favored haplotypes has been found in global wheat breeding during the past century. This research also provides a valuable case for understanding interaction of genes that control complex traits in polyploid species.

Keywords: Triticum aestivum, TaGW2, Grain weight, Gene expression, Haplotype interaction

\footnotetext{
* Correspondence: zhangxueyong@caas.cn

${ }^{\dagger}$ Equal contributors

'Key Laboratory of Crop Gene Resources and Germplasm Enhancment,

Ministry of Agriculture/The National Key Facility for Crop Gene Resources and

Genetic Improvement/Institute of Crop Science, Chinese Academy of

Agricultural Sciences, Beijing 100081, China

Full list of author information is available at the end of the article
} 


\section{Background}

Common wheat is a hexaploid species (AABBDD) with a large genome size $\left(17.9 \times 10^{9} \mathrm{bp}\right)$ and abundant repeat sequences $(>80 \%)$ [1]. Comparative genomics proved the existence of genomic colinearity among cereal crops [2]. As a model plant of cereals, the rice genomic sequence completed in 2002 [3,4], and several yield-related genes [5,6], such as GS3, GW2, GW5, GW8, TGW6, Ghd7 and GIF1, have been isolated [7-13], providing opportunities for homology-based cloning of yield-related genes in other cereals. The availability of a draft wheat genome sequence [14-17] will promote genome-based research of this extremely important crop. Cloning yield-related genes, exploring the favored alleles and developing functional markers will be important for yield improvement in that crop. This will be the next major focus of wheat genetics and genomics.

Among yield-related genes, current studies on gene function and allele discovery of GW2 are the most indepth and extensive in cereal crops. Firstly, Song et al. [8] isolated a major yield QTL from rice, which was mapped on short arm of chromosome 2 and designated as OsGW2. It encoded a RING-type protein with E3 ubiquitin ligase activity that negatively regulated grain width, and loss-offunction mutations enhanced grain weight and yield. In maize, Li et al. (2010) [18] found two homologs of OsGW2, viz. ZmGW2-CHR4 and ZmGW2-CHR5, and a SNP in the promoter region of $Z m G W 2-C H R 4$ was significantly associated with kernel width (KW) and hundred kernel weight (HKW) in maize. We cloned TaGW2 from chromosome 6A of wheat, and found SNPs in its promoter region, that were significantly associated with KW and TKW. A CAPS marker was developed based on the $-593 \mathrm{~A} / \mathrm{G}$ polymorphism and association analysis indicated that Hap-6A-A increased TKW by more than $3.1 \mathrm{~g}$ [19]. Recently, a TaGW2-6A-CAPS marker was used to detect variation in a $\mathrm{BC}_{2} \mathrm{~F}_{4}$ RIL population, as well as a natural population, further demonstrating that TaGW2$6 A$ was significantly associated with grain weight [20]. Yang et al. [21] identified a single-base insertion in the eighth exon of TaGW2-6A causing premature termination in landrace Lankaodali, which ultimately led to increased grain width and grain weight. However, Bednarek et al. [22] showed that the patterns of TaGW2 regulation of grain development might be more complex after studies on RNA interference (RNAi) of expression of TaGW2 in wheat. In consideration of the characteristics of the wheat genome, further dissection of the regulation and expression patterns of the three TaGW2 homoeologous genes on grain weight could have important biological and breeding implications.

In this study, further research focused on sequencing and diversity studies of the promoter regions of TaGW2$6 B$ and TaGW2-6D, functional marker development, and an expression pattern comparison of the three homoeologous TaGW2 loci. Hence, the major objectives were to (1) reveal sequence diversity and distribution characteristics of the three GW2 homoeologous genes by sequence alignment of their $\sim 2.9 \mathrm{~kb}$ promoter regions; (2) develop functional markers for TaGW2-6B and TaGW2-6D to distinguish various haplotypes, and discover favored haplotypes for yield improvement through association analysis; (3) evaluate the distributions of different haplotypes in global wheat major production regions, including North America, Europe, Australia, Russia, Mexico and China, and understand the selection intensity and geographical distribution of TaGW2s in different wheat ecological regions; (4) assess the relationships between the expression levels of the three TaGW2 homoeologues and grain size by real-time PCR analysis, and preliminarily evaluate the genetic effects of $T a G W 2 s$ based on phenotypic variation $\left(R^{2}\right)$ for grain traits; and (5) examine interactions among the three TaGW2 loci on chromosomes $6 \mathrm{~A}, 6 \mathrm{~B}$ and $6 \mathrm{D}$ through haplotype combination analysis. It was expected that the study would identify important genes and functional markers for wheat yield improvement.

\section{Results}

Major variations in TaGW2s occur in the promoter regions In the coding sequence of $T a G W 2$ homoeologous genes, 34 wheat accessions (Additional file 1: Table S3) were used to study the nucleotide polymorphism and no divergence was found. Genome walking was used to clone the sequences of the promoter regions of TaGW2- $6 B$ and TaGW2-6D, and $\sim 2.9 \mathrm{~kb}$ upstream sequences from the ATG start codons were obtained. The core elements of the promoters were predicted with the TSSP program (http://www.softberry.com), and the TATA box and STS (Start Transcription Site) were identified at $-159 \mathrm{bp}$ and -127 bp upstream from the ATG codon of TaGW2$6 B$. For $T a G W 2-6 D$, the corresponding locations were located at $-162 \mathrm{bp}$ and $-130 \mathrm{bp}$, respectively. Generally, more variations in TaGW2s occurred in the promoter regions, but the diversity of $T a G W 2-6 B$ was higher than that of TaGW2-6A, in which eight SNPs forming two haplotypes were found earlier [19]. No divergence was detected in the TaGW2-6D promoter region (Figure 1). Four haplotypes were formed by 11 SNPs within the $2.9 \mathrm{~kb}$ upstream sequence of TaGW2-6B; these were designated Hap-6B-1, Hap-6B-2, Hap-6B-3 and Hap-6B-4 (Figure 2).

\section{Haplotypes in promoter region of TaGW2-6B have strong effects on TKW TaGW2-6B marker development}

In the 11 SNPs detected in the TaGW2-6B promoter region (Figure 2), the nucleotide polymorphism at $-1709 \mathrm{bp}$ 


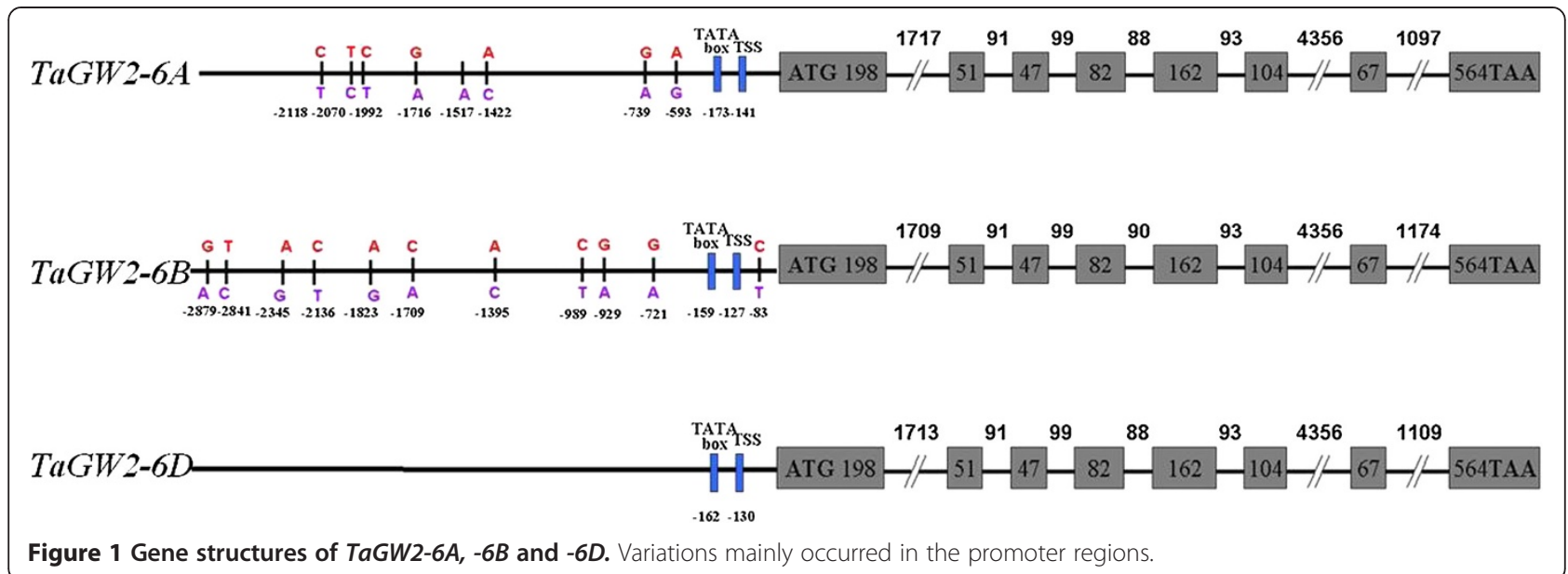

created a restriction enzyme recognition site for BstNI (CCWGG) (Figure 3A). This was employed to develop a cleaved amplified polymorphism sequence (CAPS) marker to distinguish Hap-6B-1 from the other three haplotypes. No restriction enzyme recognition site was found in Hap-6B-1 (-1709A), whereas it existed in the other three haplotypes $(-1709 \mathrm{C})$. In addition, ACASPCR primer sets designed for SNP-83 T/C worked well and were co-dominant (Figure $3 \mathrm{~B}$ ). The forward primer for ACAS-PCR was genome-specific, and the reverse was allele-specific with artificial mismatches in the 3 '-end. Hap-6B-1 and Hap-6B-2 amplified a fragment of $626 \mathrm{bp}$, whereas Hap-6B-3 and Hap-6B-4 amplified a 464 bp fragment. Thus, the ACAS-PCR primer sets reliably discriminated Hap-6B-2 and the other two haplotypes. Finally, only one SNP difference was found at -721 bp for discriminating Hap-6B-3 and Hap-6B-4. The dCAPS marker was designed with a specific mismatch in the primer to introduce a restriction enzyme Hpy166II recognition site (Figure 3C) using an available

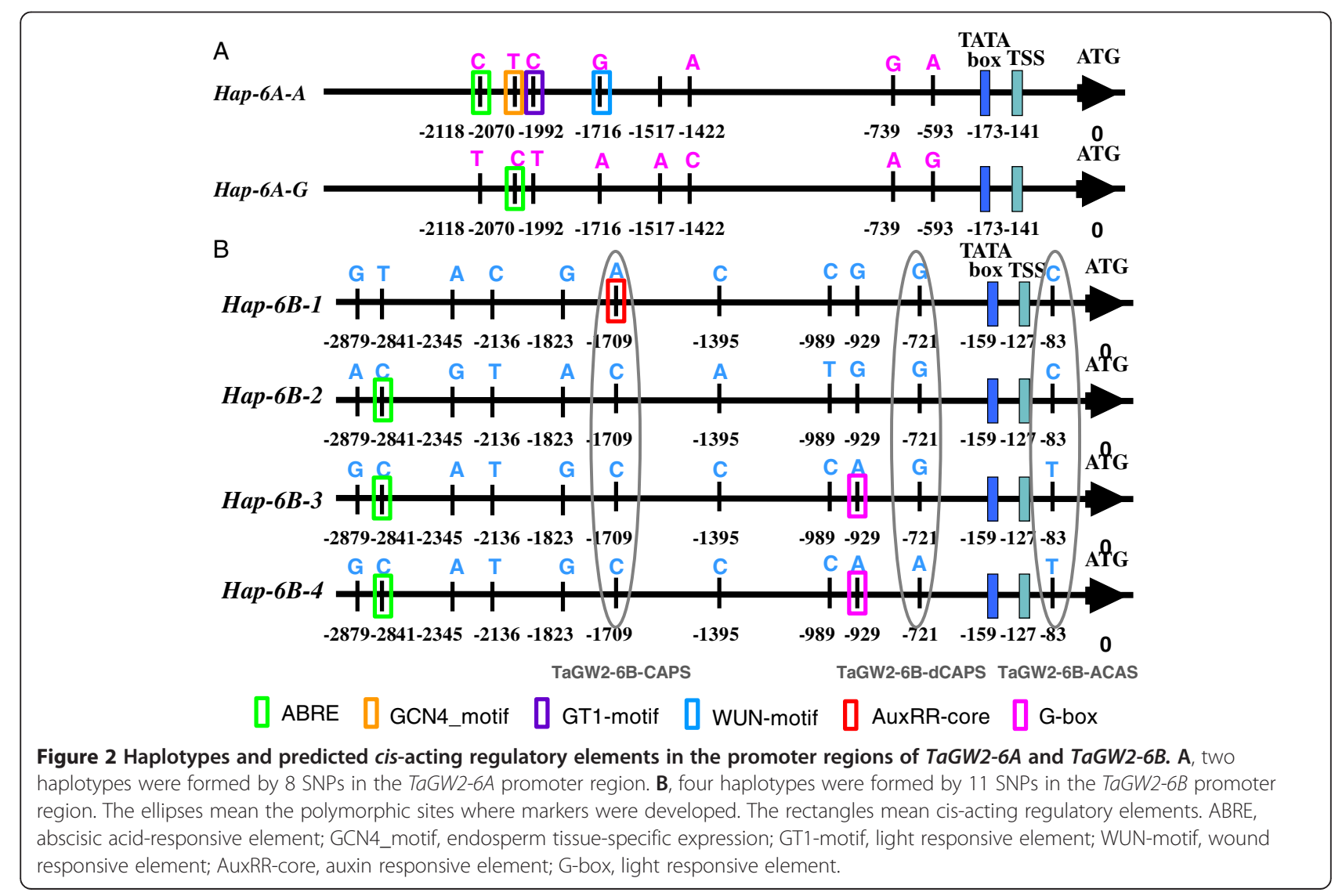




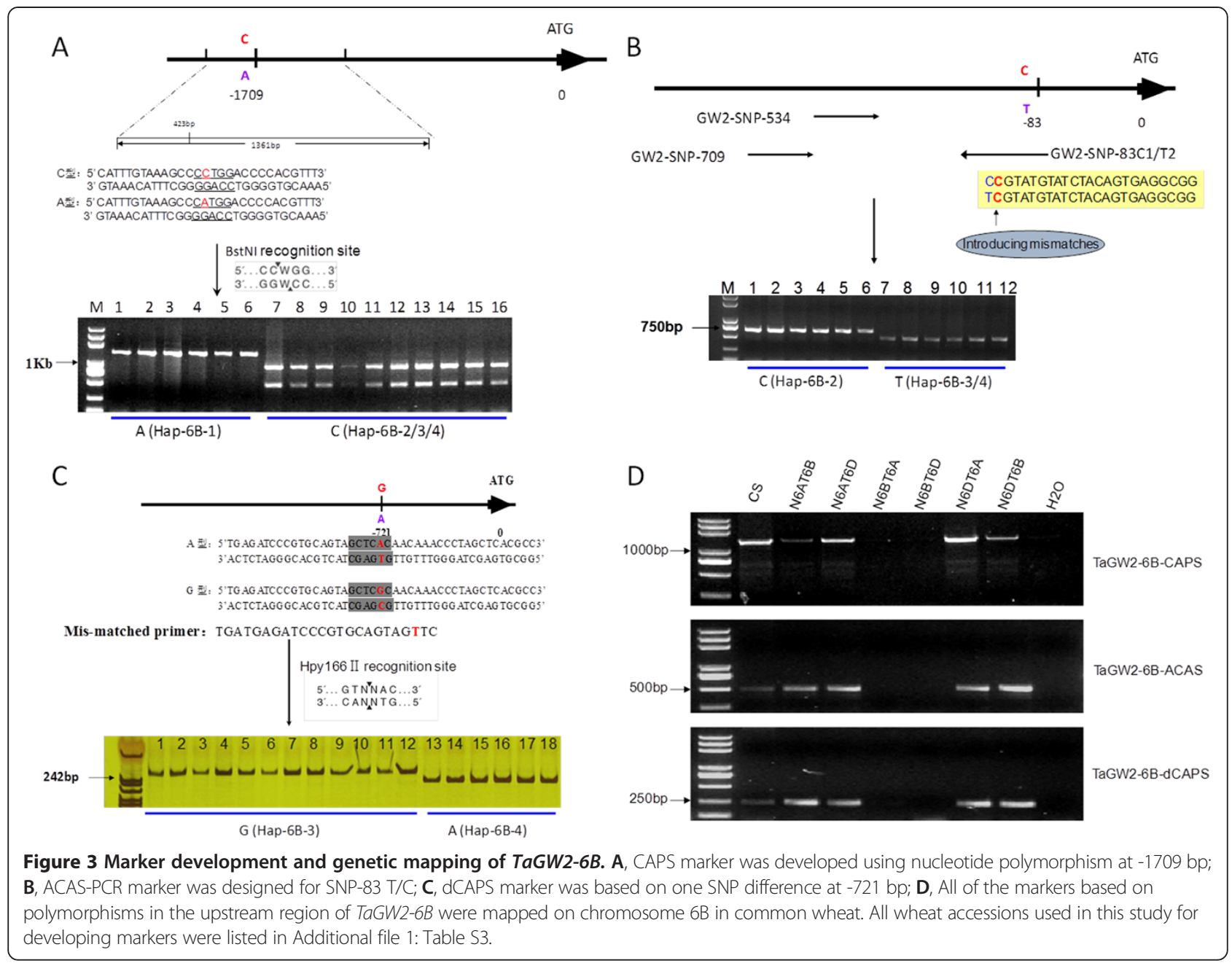

program dCAPS Finder 2.0 (http://helix.wustl.edu/ dcaps/dcaps.html). This marker effectively discriminated Hap-6B-3 (263 bp) and Hap-6B-4 (240 bp). Thus, three markers, TaGW2-6B-CAPS, TaGW2-6B-dCAPS and $T a G W 2-6 \mathrm{~B}-\mathrm{ACAS}$, were developed to distinguish these haplotypes.

Tests on a set of Chinese Spring (CS) nullisomictetrasomic lines confirmed that the three markers were chromosome 6B-specific (Figure 3D). The TaGW2-6B gene was mapped between the markers Xmag359 and Xwmc341 on chromosome 6B in the recombinant inbred line (RIL) population derived from Nanda 2419 and Wangshuibai (Additional file 2: Figure S1). Based on the wheat consensus SSR genetic map [23], TaGW2-6B was very close to the $6 \mathrm{~B}$ centromere.

\section{Strong differences in TKW and heading date exist between TaGW2-6B haplotypes}

All three molecular markers, distinguishing the four $T a G W 2-6 B$ promoter haplotypes were used for genotyping the 265 entries in the Chinese wheat mini-core collection. Previous studies had demonstrated that these accessions were clustered into two sub-populations comprising 151 landraces and 114 modern cultivars $[24,25]$ by Structure v2.1 software [26]. Therefore, association analysis between haplotypes of $T a G W 2-6 B$ and grain traits took population structure into account.

There were significant differences in TKW between Hap-6B-1 and Hap-6B-4 in the landraces $(P<0.01$ in $2002, P<0.05$ in 2006), and phenotypic differences between them were $6.38 \mathrm{~g}$ and $4.68 \mathrm{~g}$ in 2002 and 2006, respectively (Table 1$)$. This might be caused by differences in KL between Hap-6B-1 and Hap-6B-4 $(0.43 \mathrm{~mm}$ in 2002, $0.49 \mathrm{~mm}$ in 2006). Among modern cultivars, significant differences were again detected in TKW between Hap-6B-1 and Hap-6B-4 $(P<0.01$ in 2002 and 2006), and the mean TKW differences of Hap-6B-1 and Hap-6B-4 were $16.68 \mathrm{~g}$ and $15.25 \mathrm{~g}$. These differences were due to large differences in KW and KT (Table 1). KW differences between the two groups were $0.45 \mathrm{~mm}$ and $0.39 \mathrm{~mm}$, the KT differences were $0.45 \mathrm{~mm}$ and $0.33 \mathrm{~mm}$, respectively. The significant negative effect of Hap- $6 B-4$ may be the 
Table 1 TaGW2-6B haplotype associations with grain traits in two environments

\begin{tabular}{|c|c|c|c|c|c|c|c|c|}
\hline \multirow{2}{*}{$\begin{array}{l}\text { Trait/ } \\
\text { genotype }\end{array}$} & \multicolumn{4}{|l|}{$02 \mathrm{LY}$} & \multicolumn{4}{|l|}{$06 L Y$} \\
\hline & Hap-6B-1 & Hap-6B-2 & Hap-6B-3 & Hap-6B-4 & Hap-6B-1 & Hap-6B-2 & Hap-6B-3 & Hap-6B-4 \\
\hline \multicolumn{9}{|l|}{ Overall } \\
\hline $\mathrm{KL}(\mathrm{mm})$ & $6.77 \pm 0.06 a(A)$ & $6.58 \pm 0.06 \mathrm{ab}(\mathrm{AB})$ & $6.40 \pm 0.05 b c(B)$ & $6.27 \pm 0.09 c(B)$ & $6.73 \pm 0.05 a(A)$ & $6.56 \pm 0.06 a(A B)$ & $6.35 \pm 0.06 \mathrm{~b}(\mathrm{BC})$ & $6.15 \pm 0.08 b(C)$ \\
\hline KW (mm) & $3.23 \pm 0.02 \mathrm{a}(\mathrm{A})$ & $3.15 \pm 0.03 \mathrm{a}(\mathrm{A})$ & $3.04 \pm 0.02 b(B)$ & $2.91 \pm 0.04 c(B)$ & $3.29 \pm 0.02 \mathrm{a}(\mathrm{A})$ & $3.19 \pm 0.02 b(B)$ & $3.11 \pm 0.02 c(B C)$ & $3.05 \pm 0.03 c(C)$ \\
\hline $\mathrm{KT}(\mathrm{mm})$ & $2.90 \pm 0.02 \mathrm{a}(\mathrm{A})$ & $2.84 \pm 0.02 \mathrm{ab}(\mathrm{AB})$ & $2.79 \pm 0.02 b(B C)$ & $2.67 \pm 0.04 c(C)$ & $2.93 \pm 0.02 \mathrm{a}(\mathrm{A})$ & $2.86 \pm 0.02 b(A B)$ & $2.80 \pm 0.02 \mathrm{bc}(\mathrm{B})$ & $2.74 \pm 0.03 c(B)$ \\
\hline KL/KW ratio & $2.10 \pm 0.02 a$ & $2.09 \pm 0.02 a$ & $2.11 \pm 0.02 \mathrm{a}$ & $2.16 \pm 0.04 a$ & $2.05 \pm 0.02 a$ & $2.06 \pm 0.02 a$ & $2.05 \pm 0.02 a$ & $2.02 \pm 0.03 a$ \\
\hline TKW (g) & $40.39 \pm 0.71 a(A)$ & $36.72 \pm 0.88 \mathrm{~b}(\mathrm{~B})$ & $33.89 \pm 0.72 \mathrm{c}(\mathrm{BC})$ & $29.35 \pm 0.89 d(C)$ & $40.99 \pm 0.72 a(A)$ & $36.94 \pm 0.83 b(B)$ & $33.88 \pm 0.60 c(B C)$ & $31.20 \pm 0.82 c(C)$ \\
\hline \multicolumn{9}{|l|}{ Landraces } \\
\hline $\mathrm{KL}(\mathrm{mm})$ & $6.70 \pm 0.16 a$ & $6.38 \pm 0.08 a b$ & $6.36 \pm 0.06 b$ & $6.27 \pm 0.10 b$ & $6.64 \pm 0.13 a(A)$ & $6.38 \pm 0.07 a b(A B)$ & $6.33 \pm 0.06 \mathrm{ab}(\mathrm{AB})$ & $6.15 \pm 0.09 b(B)$ \\
\hline $\mathrm{KW}(\mathrm{mm})$ & $3.01 \pm 0.05 a$ & $3.01 \pm 0.03 a$ & $3.01 \pm 0.02 a$ & $2.92 \pm 0.04 a$ & $3.13 \pm 0.05 a$ & $3.11 \pm 0.02 \mathrm{a}$ & $3.10 \pm 0.02 \mathrm{a}$ & $3.06 \pm 0.03 \mathrm{a}$ \\
\hline $\mathrm{KT}(\mathrm{mm})$ & $2.79 \pm 0.05 a$ & $2.77 \pm 0.03 a$ & $2.77 \pm 0.02 a$ & $2.69 \pm 0.04 a$ & $2.83 \pm 0.04 a$ & $2.79 \pm 0.03 a$ & $2.78 \pm 0.02 a$ & $2.75 \pm 0.03 a$ \\
\hline KL/KW ratio & $2.23 \pm 0.05 a$ & $2.12 \pm 0.03 a$ & $2.12 \pm 0.02 a$ & $2.16 \pm 0.05 a$ & $2.13 \pm 0.04 a$ & $2.06 \pm 0.03 a$ & $2.05 \pm 0.02 a$ & $2.01 \pm 0.03 a$ \\
\hline TKW (g) & $36.08 \pm 2.03 a(A)$ & $32.44 \pm 1.02 \mathrm{ab}(\mathrm{AB})$ & $33.06 \pm 0.70 a b(A B)$ & $29.70 \pm 0.90 \mathrm{~b}(\mathrm{~B})$ & $36.21 \pm 1.76 a$ & $32.50 \pm 0.79 b$ & $33.29 \pm 0.60 \mathrm{ab}$ & $31.53 \pm 0.81 b$ \\
\hline \multicolumn{9}{|c|}{ Modern cultivars } \\
\hline $\mathrm{KL}(\mathrm{mm})$ & $6.79 \pm 0.06 a$ & $6.80 \pm 0.08 a$ & $6.63 \pm 0.09 a$ & $6.22 \pm 0.02 \mathrm{a}$ & $6.76 \pm 0.05 a$ & $6.76 \pm 0.10 a$ & $6.48 \pm 0.15 a$ & $6.13 \pm 0.03 a$ \\
\hline $\mathrm{KW}(\mathrm{mm})$ & $3.30 \pm 0.02 \mathrm{a}(\mathrm{A})$ & $3.30 \pm 0.03 \mathrm{a}(\mathrm{A})$ & $3.23 \pm 0.06 a(A B)$ & $2.85 \pm 0.10 \mathrm{~b}(\mathrm{~B})$ & $3.34 \pm 0.02 \mathrm{a}$ & $3.29 \pm 0.03 a b$ & $3.21 \pm 0.04 a b$ & $2.95 \pm 0.15 b$ \\
\hline $\mathrm{KT}(\mathrm{mm})$ & $2.94 \pm 0.02 \mathrm{a}(\mathrm{A})$ & $2.90 \pm 0.03 \mathrm{a}(\mathrm{A})$ & $2.91 \pm 0.05 a(A)$ & $2.49 \pm 0.11 \mathrm{~b}(\mathrm{~B})$ & $2.96 \pm 0.02 a$ & $2.94 \pm 0.02 a$ & $2.91 \pm 0.05 a b$ & $2.63 \pm 0.13 b$ \\
\hline KL/KW ratio & $2.06 \pm 0.02 \mathrm{a}$ & $2.06 \pm 0.02 a$ & $2.06 \pm 0.04 a$ & $2.19 \pm 0.08 a$ & $2.03 \pm 0.02 a$ & $2.06 \pm 0.03 a$ & $2.02 \pm 0.04 a$ & $2.09 \pm 0.12 \mathrm{a}$ \\
\hline TKW (g) & $41.77 \pm 0.59 a(A)$ & $41.32 \pm 1.08 a(A)$ & $39.71 \pm 2.16 \mathrm{a}(\mathrm{A})$ & $25.09 \pm 3.62 b(B)$ & $42.52 \pm 0.67 a(A)$ & $41.70 \pm 1.09 a(A)$ & $37.98 \pm 1.81 \mathrm{ab}(\mathrm{AB})$ & $27.27 \pm 4.39 b(B)$ \\
\hline
\end{tabular}

\section{LY, Luoyang (2002); 06LY, Luoyang (2006).}

Different capital and small letters within groups indicate significance differences between haplotypes at $P<0.01$ and $P<0.05$ for each trait, respectively.

*Hap-6B-1, landraces, $N=20$; Modern cultivars, $N=62$.

*Hap-6B-2, landraces, $N=44$; Modern cultivars, $N=41$

*Hap-6B-3, landraces, $N=63$; Modern cultivars, $N=9$.

*Hap-6B-4, landraces, $N=24$; Modern cultivars, $N=2$. 
major reason for its elimination in breeding. Compared with the other three haplotypes, Hap-6B-1 was the favored one that increased grain weight. It was noteworthy that Hap-6B-2 was quite close to Hap-6B-1 in effect on grain weight in modern Chinese cultivars.

In addition to kernel weight, haplotype association analyses of heading and maturity dates were also performed (Additional file 3: Figure S2). There were no significant differences between Hap-6B-1 and Hap-6B-4 among the landraces for the two traits, but among modern cultivars heading and maturity date differences between Hap-6B-1 and Hap-6B-4 in both growing seasons were significant. The heading dates in 2002 and 2006 differed by 13 and 9 days and the corresponding differences for maturity date were 15 and 6 days, respectively. Similarly, Hap-6B-2 was also 11 and 6 days earlier than Hap- $6 B-4$ in heading in the two seasons. For maturity, Hap-6B-2 was 13 and 4 days earlier than Hap-6B-4 in the two seasons respectively. Therefore, it seemed that Hap-6B-1 and Hap-6B-2 were associated not only with larger grain, but also earlier maturity.

\section{Geographic distribution and frequency changes among haplotypes of TaGW2-6A, and TaGW2-6B in global wheat breeding \\ Geographic distribution of TaGW2-6B haplotypes in Chinese wheats}

Wheat production in China is divided into ten ecological zones based on cultivar ecotypes, growing season, and cultivar response to temperature and photoperiod [25,27]. The distribution of TaGW2-6B haplotypes was evaluated in both landraces and modern cultivars from each zone (Figure 4). Among landraces, selection pressure on haplotypes in the different zones was not as strong as expected, and the frequency of the favored haplotype Hap-6B-1 was generally low. In the winter wheat zones III, IV, V and IX, the frequency of Hap-6B-3 was highest, whereas in spring wheat zones VI and X, Hap-6B-2 was more frequent, and Hap-6B-1 was relatively frequent only in zone VII. However, in modern cultivars, Hap-6B-1 frequencies were higher across all zones (up to 90\%), indicating it had undergone strong positive selection during wheat improvement. In detail, Hap-6B-1 was the most frequent haplotype in zones II, V, VI and VII, whereas Hap-6B-2 was most frequent in IV, VIII, IX and X. Association analysis showed that grain size and component parameters of Hap- $6 B-2$ were significantly higher than those of Hap-6B-4, although they were lower than those of Hap-6B-1 (Table 1). Compared with landraces, Hap-6B-1 and $H a p-6 B-2$ frequencies were higher across the ecological zones, presumably due to selective breeding, hence becoming the most frequent haplotypes. In contrast, the frequencies of Hap-6B-3 and Hap-6B-4 significantly decreased and even disappeared in zones IX, VI and VII (Figure 4).

Further evidence showing that $T a G W 2-6 \mathrm{~B}$ underwent strong selection in Chinese wheat breeding is provided in Figure 5. The frequency of Hap-6B-1 showed an increasing trend, especially in the 2000s (frequencies higher than 90\%). Thus this haplotype tended towards fixation during modern breeding. In contrast, Hap-6B-4 and Hap-6B-3 disappeared from cultivars released after the $1980 \mathrm{~s}$.

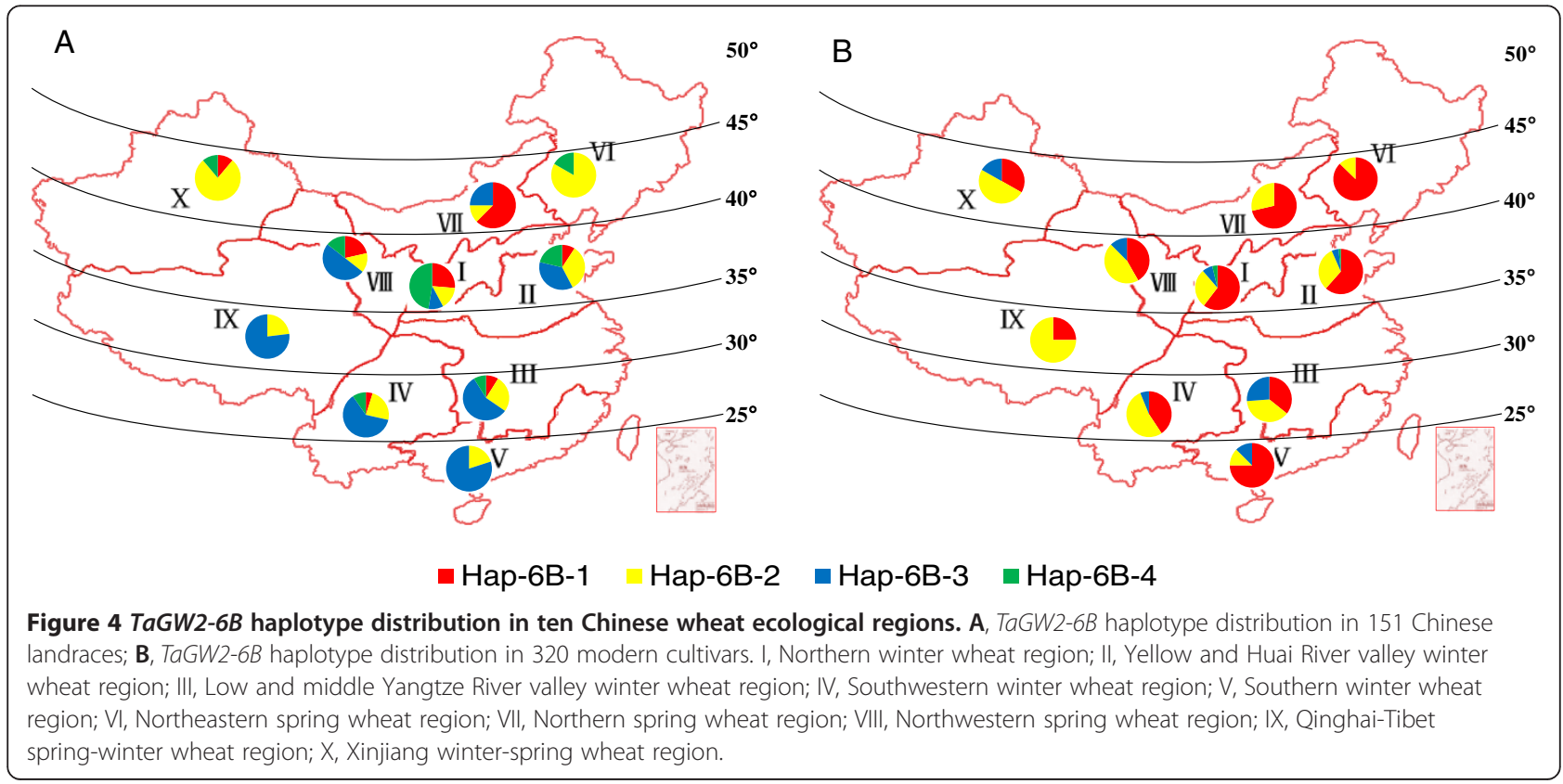




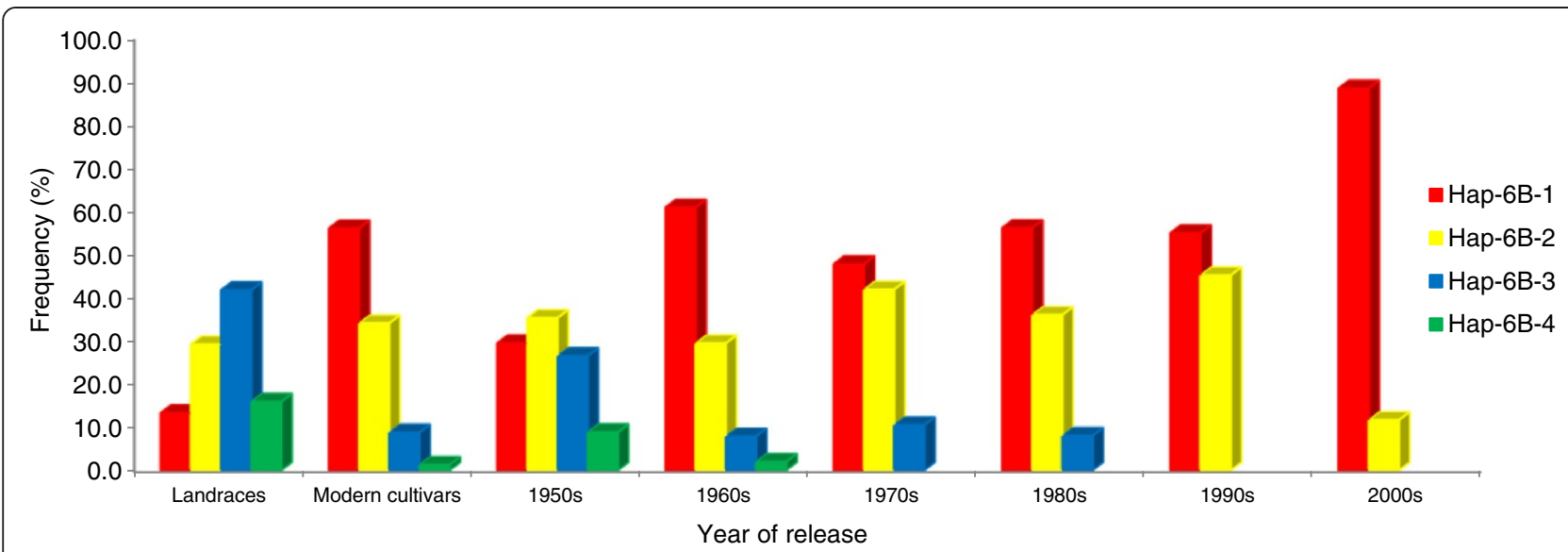

Figure 5 Haplotype frequencies of TaGW2-6B in 151 landraces and 320 modern cultivars released in different periods in China.

\section{Global distributions of haplotypes for TaGW2-6A and TaGW2-6B}

Previous study showed that Hap-6A-A was favored in China, whereas Hap-6A-G was favored in Europe [19]. In order to evaluate the distribution of all TaGW2 haplotypes in global wheat cultivars, the frequencies of haplotypes at the TaGW2-6A and TaGW2-6B loci were determined in cultivar collections from North America, Australia, China, CIMMYT, Europe and Russia (Figure 6).

Obvious geographic differences in haplotype frequencies for TaGW2-6A were found among the different groups. Hap-6A-A was more frequent in Australian, Chinese and Russian cultivars, whereas Hap-6A-G predominated in U.S., CIMMYT and European collections (Additional file 4: Figure S3). At TaGW2-6B, the superior haplotype Hap$6 B-1$ was more frequent in all regions, and Hap-6B-4 was virtually absent in all groups. Selection pressure on Hap$6 A-A$ in North America and Europe was apparently very low, in contrast to China, and Hap-6A-G tended to dominate (Additional file 4: Figure S3A-B). The favored haplotype Hap-6B-1 at TaGW2-6B showed a slow growth trend, while $H a p-6 B-4$ gradually decreased or disappeared in all continents (Additional file 4: Figure S3C-D). Therefore, an obvious consistency of globally favored haplotypes was detected at TaGW2-6B, but not at TaGW2-6A.

\section{TaGW2 genes negatively regulate wheat grain weight}

The average expression level of TaGW2-6A reached a peak at $15 \mathrm{dpf}$ and was significantly higher than that of either TaGW2-6B or TaGW2-6D in all six sampling stages of seed development (Figure 7A). The average relative expression of TaGW2-6B peaked at $10 \mathrm{dpf}$, and that of TaGW2-6D was $15 \mathrm{dpf}$. The average relative expression level of $T a G W 2-6 B$ was higher than that of TaGW2-6D in all six stages except $15 \mathrm{dpf}$.

Differences in average relative expression of TaGW2 genes were detected between the 10 higher-TKW cultivars and 12 lower-TKW genotypes. Relative expression of all TaGW2s in the lower-TKW group peaked at $15 \mathrm{dpf}$. In the other group, TaGW2-6A and TaGW2-6D also peaked at $15 \mathrm{dpf}$, but $\mathrm{TaGW2}-6 \mathrm{~B}$ peaked at $10 \mathrm{dpf}$ (Additional file 5: Figure S4). Interestingly, the average relative expression level of the three $T a G W 2$ homoeologous genes in cultivars with lower TKW was higher than that of higherTKW genotypes in developing seeds, whereas only small differences occurred in mature seeds (Additional file 5: Figure S4). This further confirmed that all three TaGW2 homoeologous genes negatively regulated grain weight.

Association analysis showed that haplotypes Hap-6A-A and Hap-6B-1 and Hap-6B-2 at TaGW2-6B were significantly associated with higher TKW, whereas Hap-6A-G and Hap-6B-4 were associated with lower TKW [19] (Table 1). The same set of 22 cultivars was used for further analysis of the relationship between relative expression levels of various $T a G W 2-6 A$ and $T a G W 2-6 B$ haplotypes and kernel traits (Additional file 6: Figure S5, Figure 7B). As shown in (Additional file 6: Figure S5), the average relative expression level of Hap-6A-G was higher than that of Hap- $6 A-A$ at all periods except $25 \mathrm{dpf}$, and was also very obvious at $15 \mathrm{dpf}$ (approximately 1.8 times higher). The average relative expression of Hap-6B-1 was lower than other haplotypes (Figure 7B), especially at $15 \mathrm{dpf}$. All of these results further suggested that TaGW2s negatively regulate grain weight by controlling the gene expression level during seed development.

\section{Additive genetic effects between favored haplotypes at TaGW2-6A and TaGW2-6B}

To reveal combination effects between haplotypes at TaGW2-6A and TaGW2-6B, an analysis was carried out on the 265 accessions mainly coming from the Chinese wheat mini core collection (Additional file 7: Figure S6, Table 2). Eight combinations of TaGW2-6A and TaGW2$6 B$ haplotypes were detected in landraces, but there were 


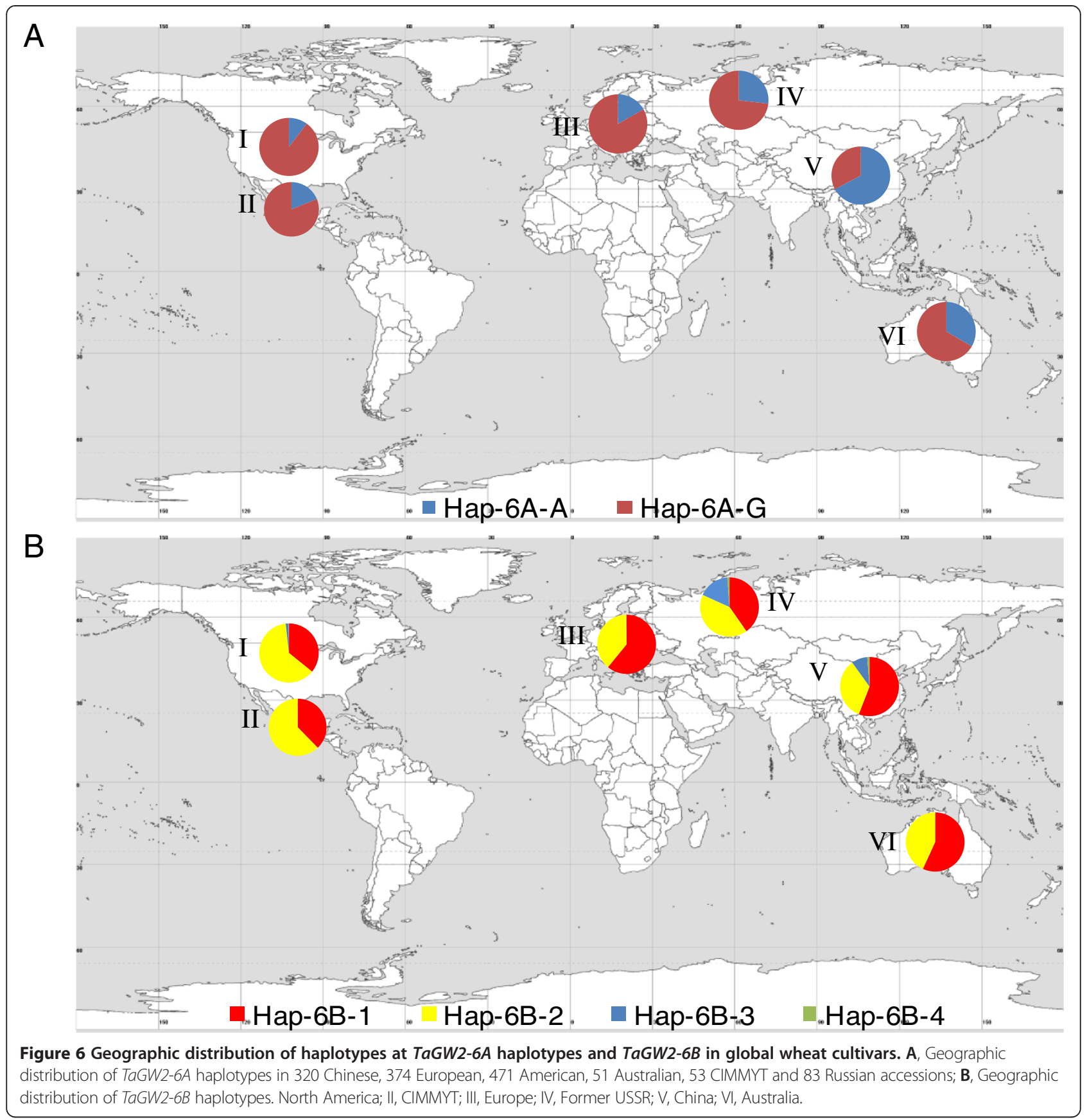

only seven in modern cultivars, the exception was Hap$6 A-A / H a p-6 B-4$ (A/4). No significant phenotypic differences were detected among these combination types in landraces (Table 2). In modern cultivars, there were significant differences between $A / 1$ (Hap-6A-A/Hap-6B-1) and G/4 (Hap-6A-G/Hap-6B-4) on KT, KW and TKW, and combination $A / 1$ was a favored type, consistent with the earlier results [19] (Table 1, Figure 8). Combination $A / 2$ (Hap-6A-A/Hap-6B-2) was close to $A / 1$, and much higher in TKW than G/4. Comparative analysis of phenotypic effects among the favored combination and superior single and other haplotypes (Figure 8) further revealed that these homoeologous genes had a strong additive effect on KW and TKW. Moreover, the favored haplotype combination $A / 1$ occurred at a higher frequency in the modern cultivars than in landraces, whereas small grained G/4 was the opposite (Additional file 8: Figure S7). These results indicate that combination $A / 1$ had undergone strong positive selection in wheat breeding due to its positive effect on grain size. 


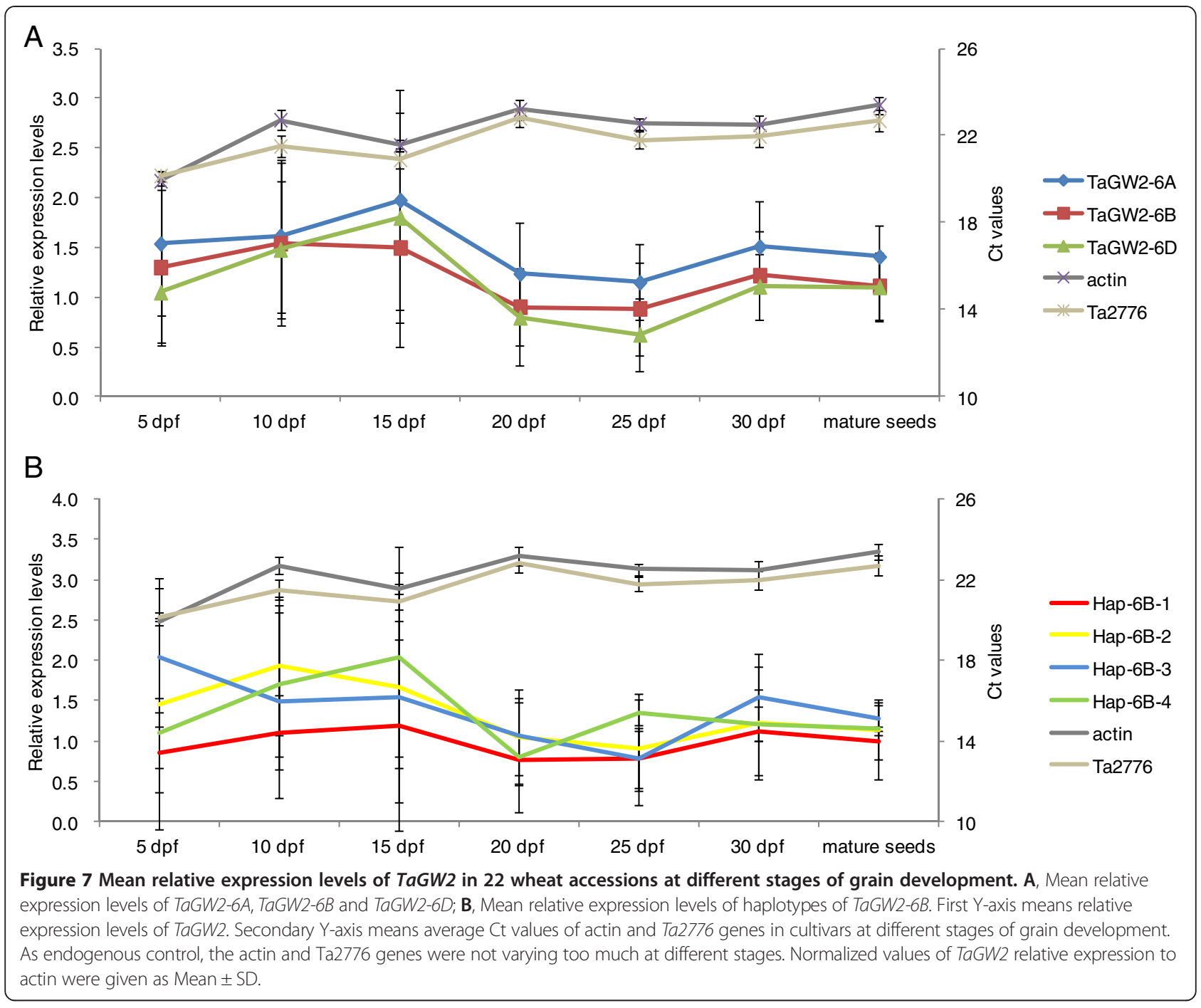

TaGW2-6B has a stronger effect than TaGW2-6A on TKW Based on the haplotype polymorphisms of TaGW2-6A and TaGW2-6B, the phenotypic explanation rates $\left(R^{2}\right)$ for grain traits was calculated in the same set of 265 accessions (Table 3). In landraces, $R^{2}$ for grain traits in TaGW2$6 B$ was higher than that in TaGW2-6A, and the value of the combination of TaGW2-6A/TaGW2-6B was higher than that of either TaGW2-6A or TaGW2-6B alone in both growing seasons (Table 3 ). As for modern cultivars, the $R^{2}$ of the combination of these two genes was still the highest, TaGW2-6B followed and TaGW2-6A was the lowest. Although they had the similar $R^{2}$ trends in these two subpopulations, $R^{2}$ of these haplotypes in the modern cultivars was significantly higher than in landraces, especially for KW and TKW. This further indicated that these grain trait-related genes had undergone strong positive selection in modern breeding, and that TaGW2 controlled grain weight in terms of regulating grain width during development. In addition, the $R^{2}$ values of the TaGW2-6A/
TaGW2-6B combination were higher than those of TaGW2-6A plus TaGW2-6B for all grain traits in two environments in the landraces. However, in modern cultivars, the phenotypic effect of the combination of these two haplotypes was less than that of their simple sum.

\section{Discussion}

Natural diversity in cereal yield genes usually occurs in promoter and intron regions that influence gene expression levels

The isolation of genes controlling grain weight in wheat and development of functional markers are desirable for marker-assisted-selection (MAS) breeding. On the basis of genetic information, several successful examples of MAS combined with phenotypic measurement have been accomplished, and these have mainly focused on improvement of discontinuous traits such as resistance to pests/ disease, stress tolerance, and grain quality [28-39]. Liu et al. [40] recently reviewed progress in functional marker 
Table 2 Effects of TaGW2-6A and TaGW2-6B haplotype interaction on grain traits in two environments

\begin{tabular}{|c|c|c|c|c|c|c|c|c|}
\hline \multirow[t]{2}{*}{ Trait/genotype } & \multicolumn{8}{|c|}{$02 L Y$} \\
\hline & $A / 1$ & $A / 2$ & $A / 3$ & $A / 4$ & $G / 1$ & $G / 2$ & $G / 3$ & $G / 4$ \\
\hline \multicolumn{9}{|l|}{ Overall } \\
\hline $\mathrm{KL}(\mathrm{mm})$ & $6.79 \pm 0.07 a(A)$ & $6.66 \pm 0.08 \mathrm{abc}(\mathrm{AB})$ & $6.36 \pm 0.06 \mathrm{bc}(\mathrm{B})$ & $6.11 \pm 0.17 \mathrm{abc}(\mathrm{AB})$ & $6.73 \pm 0.11 \mathrm{ac}(\mathrm{AB})$ & $6.51 \pm 0.09 \mathrm{abc}(\mathrm{AB})$ & $6.44 \pm 0.08 \mathrm{abc}(\mathrm{AB})$ & $6.31 \pm 0.10 c(B)$ \\
\hline $\mathrm{KW}(\mathrm{mm})$ & $3.28 \pm 0.03 a(A)$ & $3.25 \pm 0.03 a(A)$ & $3.05 \pm 0.03 b(B C)$ & $3.05 \pm 0.03 a b c(A B C)$ & $3.15 \pm 0.04 a b(A B)$ & $3.06 \pm 0.03 b(B C)$ & $3.03 \pm 0.03 \mathrm{bc}(\mathrm{BC})$ & $2.88 \pm 0.04 c(C)$ \\
\hline $\mathrm{KT}(\mathrm{mm})$ & $2.91 \pm 0.03 \mathrm{a}(\mathrm{A})$ & $2.89 \pm 0.03 a b(A)$ & $2.78 \pm 0.03 b(A B)$ & $2.86 \pm 0.05 \mathrm{abc}(\mathrm{AB})$ & $2.89 \pm 0.03 a b(A)$ & $2.79 \pm 0.03 b(A B)$ & $2.80 \pm 0.03 a b(A B)$ & $2.63 \pm 0.04 c(B)$ \\
\hline $\mathrm{KL} / \mathrm{KW}$ ratio & $2.08 \pm 0.02 \mathrm{ab}$ & $2.05 \pm 0.02 a$ & $2.09 \pm 0.02 \mathrm{ab}$ & $2.00 \pm 0.04 a b$ & $2.15 \pm 0.03 a b$ & $2.13 \pm 0.03 a b$ & $2.13 \pm 0.03 a b$ & $2.20 \pm 0.05 b$ \\
\hline TKW (g) & $41.33 \pm 0.80 a(A)$ & $39.35 \pm 1.25 a(A C D)$ & $33.57 \pm 0.91 \mathrm{bc}(\mathrm{BE})$ & $33.34 \pm 1.64 a b c(A B E)$ & $38.98 \pm 1.28 \mathrm{ab}(\mathrm{AB})$ & $34.59 \pm 1.16 \mathrm{~b}(\mathrm{BCE})$ & $34.35 \pm 1.17 \mathrm{~b}(\mathrm{BDE})$ & $28.39 \pm 0.93 c(E)$ \\
\hline \multicolumn{9}{|l|}{ Landraces } \\
\hline $\mathrm{KL}(\mathrm{mm})$ & $6.71 \pm 0.21 a$ & $6.40 \pm 0.11 a$ & $6.33 \pm 0.07 a$ & $6.11 \pm 0.17 a$ & $6.70 \pm 0.23 a$ & $6.37 \pm 0.10 \mathrm{a}$ & $6.41 \pm 0.09 a$ & $6.32 \pm 0.12 a$ \\
\hline $\mathrm{KW}(\mathrm{mm})$ & $3.02 \pm 0.05 a b(A B)$ & $3.11 \pm 0.05 \mathrm{a}(\mathrm{A})$ & $3.01 \pm 0.03 \mathrm{ab}(\mathrm{AB})$ & $3.05 \pm 0.03 \mathrm{ab}(\mathrm{AB})$ & $3.01 \pm 0.08 \mathrm{ab}(\mathrm{AB})$ & $2.97 \pm 0.03 a b(A B)$ & $3.01 \pm 0.03 \mathrm{ab}(\mathrm{AB})$ & $2.88 \pm 0.04 b(B)$ \\
\hline $\mathrm{KT}(\mathrm{mm})$ & $2.67 \pm 0.07 a b$ & $2.79 \pm 0.06 a b$ & $2.76 \pm 0.03 a b$ & $2.86 \pm 0.05 a b$ & $2.87 \pm 0.06 a$ & $2.76 \pm 0.04 a b$ & $2.79 \pm 0.03 a b$ & $2.64 \pm 0.05 b$ \\
\hline $\mathrm{KL} / \mathrm{KW}$ ratio & $2.23 \pm 0.08 a$ & $2.06 \pm 0.04 a$ & $2.11 \pm 0.02 \mathrm{a}$ & $2.00 \pm 0.04 a$ & $2.23 \pm 0.06 a$ & $2.15 \pm 0.03 a$ & $2.13 \pm 0.03 a$ & $2.20 \pm 0.05 a$ \\
\hline TKW(g) & $34.38 \pm 2.55 \mathrm{ab}(\mathrm{AB})$ & $34.33 \pm 1.76 \mathrm{ab}(\mathrm{AB})$ & $32.63 \pm 0.84 a b(A B)$ & $33.34 \pm 1.64 \mathrm{ab}(\mathrm{AB})$ & $37.22 \pm 2.96 \mathrm{a}(\mathrm{A})$ & $31.64 \pm 1.24 a b(A B)$ & $33.68 \pm 1.22 \mathrm{ab}(\mathrm{AB})$ & $28.74 \pm 0.95 b(B)$ \\
\hline \multicolumn{9}{|l|}{ Modern cultivars } \\
\hline $\mathrm{KL}(\mathrm{mm})$ & $6.81 \pm 0.08 a$ & $6.79 \pm 0.10 a$ & $6.59 \pm 0.16 a$ & & $6.75 \pm 0.11 a$ & $6.80 \pm 0.15 a$ & $6.68 \pm 0.05 a$ & $6.22 \pm 0.02 a$ \\
\hline $\mathrm{KW}(\mathrm{mm})$ & $3.33 \pm 0.02 a(A)$ & $3.33 \pm 0.04 a(A)$ & $3.29 \pm 0.06 a b(A B)$ & & $3.23 \pm 0.04 a b(A B)$ & $3.24 \pm 0.05 a b(A B)$ & $3.15 \pm 0.09 a b(A B)$ & $2.85 \pm 0.10 \mathrm{~b}(\mathrm{~B})$ \\
\hline $\mathrm{KT}(\mathrm{mm})$ & $2.96 \pm 0.02 a(A)$ & $2.95 \pm 0.04 a(A)$ & $2.94 \pm 0.05 a(A B)$ & & $2.90 \pm 0.03 a(A B)$ & $2.84 \pm 0.05 a b(A B)$ & $2.88 \pm 0.11 \mathrm{ab}(\mathrm{AB})$ & $2.49 \pm 0.11 b(B)$ \\
\hline KL/KW ratio & $2.05 \pm 0.02 \mathrm{a}$ & $2.04 \pm 0.02 \mathrm{a}$ & $2.00 \pm 0.03 a$ & & $2.10 \pm 0.04 a$ & $2.10 \pm 0.05 a$ & $2.13 \pm 0.08 a$ & $2.19 \pm 0.08 a$ \\
\hline \multirow[t]{3}{*}{ TKW(g) } & $42.68 \pm 0.65 a(A)$ & $41.97 \pm 1.41 \mathrm{a}(\mathrm{A})$ & $40.53 \pm 3.09 a(A B)$ & & $39.99 \pm 1.11 \mathrm{a}(\mathrm{A})$ & $40.30 \pm 1.69 a(A)$ & $38.69 \pm 3.37 \mathrm{ab}(\mathrm{AB})$ & $25.09 \pm 3.62 \mathrm{~b}(\mathrm{~B})$ \\
\hline & \multicolumn{8}{|c|}{$06 \mathrm{LY}$} \\
\hline & $A / 1$ & $A / 2$ & $A / 3$ & $A / 4$ & $G / 1$ & $G / 2$ & $G / 3$ & $G / 4$ \\
\hline \multicolumn{9}{|l|}{ Overall } \\
\hline $\mathrm{KL}(\mathrm{mm})$ & $6.71 \pm 0.06 \mathrm{a}(\mathrm{A})$ & $6.60 \pm 0.10 \mathrm{ab}(\mathrm{AB})$ & $6.30 \pm 0.07 b c(B)$ & $6.05 \pm 0.13 \mathrm{abc}(\mathrm{AB})$ & $6.75 \pm 0.09 a(A)$ & $6.53 \pm 0.08 \mathrm{abc}(\mathrm{AB})$ & $6.42 \pm 0.10 \mathrm{abc}(\mathrm{AB})$ & $6.17 \pm 0.09 c(B)$ \\
\hline $\mathrm{KW}(\mathrm{mm})$ & $3.34 \pm 0.03 a(A)$ & $3.24 \pm 0.03 \mathrm{acd}(\mathrm{AB})$ & $3.12 \pm 0.03 \mathrm{bf}(\mathrm{BC})$ & $3.12 \pm 0.07 a b f(A B C)$ & $3.20 \pm 0.04 b c(A B C)$ & $3.15 \pm 0.03 \mathrm{bdf}(\mathrm{BC})$ & $3.10 \pm 0.02 \mathrm{bef}(\mathrm{BC})$ & $3.03 \pm 0.03 f(C)$ \\
\hline $\mathrm{KT}(\mathrm{mm})$ & $2.93 \pm 0.03 a(A)$ & $2.86 \pm 0.03 a b(A B)$ & $2.76 \pm 0.02 \mathrm{bc}(\mathrm{B})$ & $2.83 \pm 0.04 a b c(A B)$ & $2.93 \pm 0.03 \mathrm{a}(\mathrm{A})$ & $2.85 \pm 0.03 \mathrm{abc}(\mathrm{AB})$ & $2.85 \pm 0.02 \mathrm{abc}(\mathrm{AB})$ & $2.72 \pm 0.03 c(B)$ \\
\hline $\mathrm{KL} / \mathrm{KW}$ ratio & $2.01 \pm 0.02 \mathrm{a}$ & $2.04 \pm 0.03 a$ & $2.02 \pm 0.02 \mathrm{a}$ & $1.95 \pm 0.07 a$ & $2.11 \pm 0.03 a$ & $2.08 \pm 0.03 a$ & $2.07 \pm 0.03 a$ & $2.04 \pm 0.03 a$ \\
\hline TKW (g) & $41.85 \pm 0.84 a(A)$ & $39.09 \pm 1.25 \mathrm{acde}(\mathrm{AC})$ & $33.38 \pm 0.83 b(B)$ & $32.48 \pm 2.09 \mathrm{cb}(\mathrm{AB})$ & $39.70 \pm 1.28 \mathrm{ac}(\mathrm{AC})$ & $35.19 \pm 1.05 \mathrm{bd}(\mathrm{BC})$ & $34.57 \pm 0.83 \mathrm{be}(\mathrm{BC})$ & $30.89 \pm 0.90 \mathrm{bf}(\mathrm{BD})$ \\
\hline \multicolumn{9}{|l|}{ Landraces } \\
\hline $\mathrm{KL}(\mathrm{mm})$ & $6.52 \pm 0.20 \mathrm{a}$ & $6.33 \pm 0.11 a$ & $6.26 \pm 0.07 a$ & $6.05 \pm 0.13 a$ & $6.72 \pm 0.18 a$ & $6.40 \pm 0.09 a$ & $6.42 \pm 0.11 a$ & $6.18 \pm 0.10 \mathrm{a}$ \\
\hline $\mathrm{KW}(\mathrm{mm})$ & $3.13 \pm 0.08 a$ & $3.12 \pm 0.04 a$ & $3.10 \pm 0.03 a$ & $3.12 \pm 0.07 a$ & $3.13 \pm 0.07 a$ & $3.10 \pm 0.03 a$ & $3.10 \pm 0.03 a$ & $3.04 \pm 0.03 a$ \\
\hline $\mathrm{KT}(\mathrm{mm})$ & $2.74 \pm 0.07 a$ & $2.73 \pm 0.03 a$ & $2.74 \pm 0.03 a$ & $2.83 \pm 0.04 a$ & $2.88 \pm 0.05 a$ & $2.81 \pm 0.04 a$ & $2.83 \pm 0.03 a$ & $2.73 \pm 0.03 a$ \\
\hline $\mathrm{KL} / \mathrm{KW}$ ratio & $2.09 \pm 0.07 a$ & $2.03 \pm 0.04 a$ & $2.03 \pm 0.03 a$ & $1.95 \pm 0.07 a$ & $2.15 \pm 0.06 a$ & $2.07 \pm 0.03 a$ & $2.08 \pm 0.04 a$ & $2.03 \pm 0.03 a$ \\
\hline TKW (g) & $34.22 \pm 2.28 a b$ & $33.24 \pm 1.21 a b$ & $32.69 \pm 0.83 a b$ & $32.48 \pm 2.09 a b$ & $37.55 \pm 2.51 \mathrm{a}$ & $32.19 \pm 1.00 a b$ & $34.15 \pm 0.83 a b$ & $31.27 \pm 0.89 b$ \\
\hline
\end{tabular}


Table 2 Effects of TaGW2-6A and TaGW2-6B haplotype interaction on grain traits in two environments (Continued)

\begin{tabular}{|c|c|c|c|c|c|c|c|}
\hline \multicolumn{8}{|c|}{ Modern cultivars } \\
\hline \multicolumn{8}{|c|}{$\mathrm{KL}(\mathrm{mm})$} \\
\hline $\mathrm{KW}(\mathrm{mm})$ & $3.38 \pm 0.02 a$ & $3.31 \pm 0.04 a b$ & $3.28 \pm 0.05 a b$ & $3.24 \pm 0.04 a b$ & $3.25 \pm 0.05 a b$ & $3.11 \pm 0.03 \mathrm{ab}$ & $2.95 \pm 0.15 b$ \\
\hline $\mathrm{KT}(\mathrm{mm})$ & $2.97 \pm 0.02 a$ & $2.93 \pm 0.03 a b$ & $2.89 \pm 0.07 a b$ & $2.95 \pm 0.03 a b$ & $2.95 \pm 0.04 a b$ & $2.94 \pm 0.06 a b$ & $2.63 \pm 0.13 b$ \\
\hline $\mathrm{KL} / \mathrm{KW}$ ratio & $2.00 \pm 0.02 a$ & $2.04 \pm 0.04 a$ & $1.99 \pm 0.05 a$ & $2.09 \pm 0.04 a$ & $2.09 \pm 0.04 a$ & $2.06 \pm 0.08 a$ & $2.09 \pm 0.12 a$ \\
\hline TKW (g) & $43.34 \pm 0.70 a(A)$ & $42.14 \pm 1.47 a(A B)$ & $38.47 \pm 2.49 \mathrm{ab}(\mathrm{AB})$ & $40.93 \pm 1.39 a(A B)$ & $41.01 \pm 1.65 a(A B)$ & $37.36 \pm 3.02 \mathrm{ab}(\mathrm{AB})$ & $27.27 \pm 4.39 b(B)$ \\
\hline
\end{tabular}

D2LY, Luoyang (2002); 06LY, Luoyang (2006).

Different capital and small letters indicate significant between hapl.
${ }^{*} A / 1$, Hap-6A-A/Hap-6B-1; landraces, $N=8$; Modern cultivars, $N=41$.

${ }^{*} A / 2$, Hap-6A-A/Hap-6B-2; landraces, $N=13$; Modern cultivars, $N=25$.

${ }^{*} A / 3$, Hap- $6 A-A /$ Hap $-6 B-3$; landraces, $N=37$; Modern cultivars, $N=5$.

${ }^{*} A / 4$, Hap-6A-A/Hap-6B-4; landraces, $N=5$; Modern cultivars, $N=0$.

${ }^{*} G / 1$, Hap-6A-G/Hap-6B-1; landraces, $N=12$; Modern cultivars, $N=21$.

${ }^{*} G / 2$, Hap-6A-G/Hap-6B-2; landraces, $N=31$; Modern cultivars, $N=16$.

${ }^{*} G / 3$, Hap- $6 A-G /$ Hap- $6 B-3 ;$ landraces, $N=26 ;$ Modern cultivar, $N=4$.

${ }^{*} \mathrm{G} / 4$, Hap-6A-G/Hap-6B-4; landraces, $\mathrm{N}=19$; Modern cultivars, $\mathrm{N}=2$. 


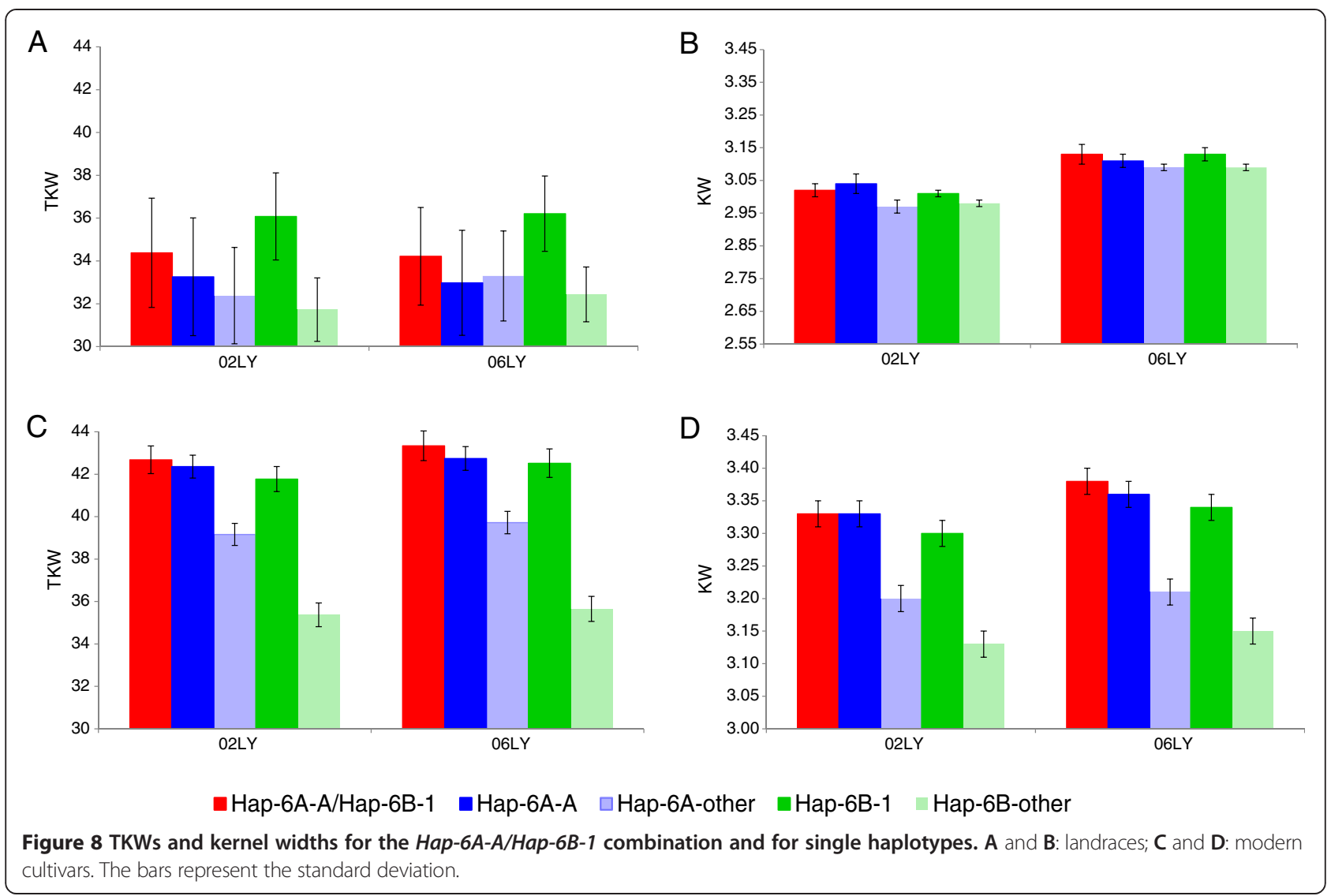

development in wheat, including the 97 markers associated with processing quality, agronomic traits and disease resistance. In this review, three markers for wheat grain weight genes were also mentioned; they were TaSus $2-2 B$, TaGW2-6A and TaCwi-A1 [19,41,42], respectively. Among them, the CAPS marker of TaGW2-6A distinguished Hap-6A-A and Hap-6A-G with higher accuracy and repeatability, making it an effective marker for selection of kernel weight [43].

In some cereal yield genes, natural diversity usually occurred in promoter or intron regions, which influenced gene expression levels. For example, the differences in expression levels of GS5 in rice are attributable to polymorphisms in the promoter region, leading to grain

Table 3 Phenotypic explanation rates $\left(R^{2}\right)$ of TaGW2-6A, TaGW2-6B and their combinations for grain traits in landrace and modern cultivar subpopulations in two environments

\begin{tabular}{|c|c|c|c|c|c|c|}
\hline \multirow[t]{2}{*}{ Item } & \multicolumn{3}{|c|}{$02 \mathrm{LY}$} & \multicolumn{3}{|c|}{$06 L Y$} \\
\hline & TaGW2-6A & TaGW2-6B & TaGW2-6A/TaGW2-6B & TaGW2-6A & TaGW2-6B & TaGW2-6A/TaGW2-6B \\
\hline \multicolumn{7}{|l|}{ Landraces } \\
\hline TKW (g) & 0.44 & 7.17 & 10.40 & 0.09 & 6.19 & 8.52 \\
\hline $\mathrm{KL}(\mathrm{mm})$ & 0.13 & 5.77 & 6.41 & 1.12 & 6.81 & 8.57 \\
\hline $\mathrm{KW}(\mathrm{mm})$ & 3.58 & 3.76 & 9.76 & 0.27 & 1.58 & 2.33 \\
\hline $\mathrm{KT}(\mathrm{mm})$ & 0.01 & 2.71 & 9.57 & 3.47 & 1.62 & 9.52 \\
\hline \multicolumn{7}{|c|}{ Modern cultivars } \\
\hline TKW (g) & 5.79 & 13.54 & 16.82 & 3.94 & 12.88 & 14.99 \\
\hline $\mathrm{KL}(\mathrm{mm})$ & 0.26 & 3.23 & 3.49 & 0.03 & 4.84 & 5.04 \\
\hline $\mathrm{KW}(\mathrm{mm})$ & 9.73 & 10.51 & 17.36 & 10.55 & 9.73 & 18.38 \\
\hline $\mathrm{KT}(\mathrm{mm})$ & 8.31 & 12.08 & 17.79 & 0.36 & 8.55 & 8.97 \\
\hline
\end{tabular}

02LY, Luoyang (2002); 06LY, Luoyang (2006). 
width variation [44]. Another good example is that one polymorphism in the promoter region of ZmGS3 was found to affect HKW in two environments [45]. It is also found that one SNP in the promoter region of $Z m G W 2$ CHR4 was significantly associated with KW and HKW, and the expression level of this gene was negatively correlated with KW [18]. Further analysis of polymorphism in the TaGW2-6B and TaGW2-6D diversity in this study showed that most of the diversity existed in the promoter region of TaGW2-6B, with no diversity in TaGW2-6D (Figure 1). This is consistant with findings for yield gene diversity in rice [5] and maize [18,45]. In addition, the diversity of wheat yield gene TaDep1 and TaSUS1-7B were also found in intron regions, which influenced gene expression levels [46,47].

Association analysis of grain traits suggested that Hap6B-1 and Hap-6B-2 were favored haplotypes (Table 1), and the TaGW2-6B-CAPS markers could distinguish the favored haplotypes from other haplotypes, indicating that they could be used as diagnostic markers in MAS for increased grain weight.

The average TKW of Hap-6A-A was about $3.1 \mathrm{~g}$ higher than that of Hap-6A-G in Chinese modern cultivars [19]. Moreover, genotypes with the Hap-6A-A allele had earlier heading and maturity dates of about 3.5 and 2.5 days than Hap-6A-G genotypes. In this study, the favored haplotype Hap-6B-1 also affected wheat maturity, with earlier heading and maturity dates compared to other haplotypes (Additional file 3: Figure S2). This may be caused by: (1) a hitchhiking effect of a developmentally-related gene during selection of Hap-6B-1 in domestication and breeding; genes affecting maturity have been mapped near the chromosome group 6 centromere regions [48], or (2) a pleiotropic effect of TaGW2. The additive effect of TaGW2-6A combined with TaGW2-6B showed that Hap-6A-A/Hap-6B-1 was a superior combination conferring high TKW in modern cultivars (Table 2, Figure 8), although is effect in landraces was not. The combination effect of the two favored haplotypes was significantly higher than that of any single haplotype (Figure 8), indicating an obvious additive effect.

\section{Strong selection of TaGW2-6A and TaGW2-6B haplotypes occurred in global wheat breeding}

In most domesticated crops, genetic diversity differs under conditions of continuous natural and artificial selection. In this process, about 2 to $4 \%$ of maize genes (a minimum of 1,200 ) throughout the genome were targeted for selection during domestication and improvement [49], and many genes, such as the Waxy gene in rice [50], heightreduction genes $R h t-B 1$ and $R h t-D 1$ in wheat [51], and the tomato fruit size gene fw2.2 [52] had retained a selection trace. Grain weight is a quantitative trait controlled by multiple genes and is also positively selected during domestication and breeding. In modern wheat breeding, genes controlling yield traits have undergone strong artificial selection and the frequency distributions of their variations are extremely uneven, and the alleles associated with ecological adaptation and favored agronomic traits are present at high frequency [53-55].

Our previous study investigated the distribution of TaGW2-6A haplotypes in Chinese and European wheat cultivars [19]. In this study, the distribution of TaGW2-6A and TaGW2-6B haplotypes are systematically described for six major regional wheat production regions worldwide, viz. China, US, Canada, Russia, Australia, Europe and Mexico (Figure 6). Haplotype Hap-6A-A at TaGW2$6 A$ was favored in cultivars released in China, Australia and Russia, whereas Hap-6A-G was frequent in other areas. In addition, Hap- $6 A-A$ was mainly distributed in spring and weak-winter wheat cultivars with early maturity, which was favorable to increasing the multi-cropping index, whereas in winter and strong-winter wheat cultivars Hap-6A-G was more frequent. This geographic difference in TaGW2-6A haplotypes may be related to the breeding and planting environment. In contrast, the distribution of favored TaGW2- $6 B$ haplotypes tended to be more consistent across global wheat cultivars, and favored haplotypes Hap-6B-1 and Hap-6B-2 have undergone strong positive selection and accumulation in breeding programs.

TaGW2 negatively regulates grain weight, genotypes with lower expression were positively selected in breeding

In recent years scientists have been searching for key genes controlling kernel weight in cereals because it is a major component of yield. In rice, GS3, GW2 and $q S W 5$ negatively regulate grain size $[7,8,56]$. In contrast, $G W 8$ and GS5 were isolated as positive regulators of grain size, and their higher expression levels could be involved in promoting cell division and ultimately increasing grain yield [10,44]. A comparative genomics study found that the expression level of the $Z m G W 2-C H R 4$ gene was negatively correlated with grain weight in maize [18], and shared the same regulation pattern as GW2 in rice. Gene TaGW2 regulated grain size in wheat through variation in expression level [19]. SNPs in the TaGW2-6A promoter region may be related to expression of different alleles, such as Hap-6A-A and Hap-6A-G. The regulation pattern of TaGW2-6A was consistent with OsGW2, both of which negatively regulated grain width and weight [8]. Yang et al. [21] identified a $1 \mathrm{bp}$ insertion at the 977th base pair of TaGW2-6A in cultivar Lankaodali and a derived SNP marker was used to genotype an $\mathrm{F}_{2}$ population derived from a cross of Lankaodali (TT) and Chinese Spring (tt). Compared with the tt genotype, the average increase in TT genotypes was $0.18 \mathrm{~mm}$ for KW and $3.94 \mathrm{~g}$ for TKW, 
indicating that $T a G W 2-6 A$ regulated grain width and grain weight. However, Bednarek et al. [22] showed that RNAi resulted in down-regulation of TaGW2 expression in wheat, inducing significant decreases in grain parameters (viz. final grain fresh, dry and irrigation masses, and grain volume, width, and thickness). They concluded that $T a G W 2$ positively regulated grain size in wheat. For relative expression analysis RT-PCR was performed at different seed development periods after flowering in the present study (Additional file 6: Figure S5), in order to objectively evaluate the relationship between gene expression and grain size/weight. Our results showed that the relative expression levels of the TaGW2-A/B/D orthologs in developing seeds were all negatively correlated with grain width/weight.

The cis-elements in promoter regions of TaGW2-6A and TaGW2-6B were predicted by Plantcare. More cis-elements were found on Hap-6A-A than on Hap-6A-G. Due to the $\mathrm{SNP}$ at $-2070 \mathrm{bp}$, there is an endosperm tissue-specific expression element GCN4_motif in Hap-6A-A, but in corresponding region of Hap-6A-G, it is an ABA response element, ABRE (Figure 2). For TaGW2-6B locus, at -929 bp, a G-box was detected in Hap-6B-3 and Hap$6 B-4$, an auxin responsive element (AuxRR-core) was found in Hap-6B-1 at -1709 bp, an ABRE was detected in Hap-6B-2, Hap-6B-3 and Hap-6B-4 (Figure 2). The influence of these cis-elements on TaGW2 expression need to be further elucidated in the future.

Moreover, the average relative expression level of TaGW2-6A was higher than that of TaGW2-6B and TaGW2-6D, and the phenotypic explanation rate $\left(R^{2}\right)$ for grain traits explained by $T a G W 2-6 B$ was higher than that of TaGW2-6A in both landraces and modern cultivars (Table 3). Therefore, the lower the relative expression level of a TaGW2 gene, the higher its $R^{2}$ value, indicating that grain size is negatively regulated by $T a G W 2$ genes. Thus among the three TaGW2 homoeologous genes, the average expression of TaGW2-6A during the grain development was the highest, but its $R^{2}$ was the lowest. TaGW2-6D gene was the most conservative with the lowest mean expression among the three homoeologous genes, and its $R^{2}$ was estimated to be the highest. There are three possible reasons for lack of diversity at TaGW2$6 D$ locus. Firstly, during evolution from tetraploid to hexaploid wheat, the increase in KW was larger than that in KL. Secondly, the D genome has much lower diversity than the A- or B- genomes in common wheat $[57,58]$. Thirdly, TaGW2-6D has the strongest effect on TKW, and it underwent strong positive selection and fixation in early domestication of hexaploid wheat (Table 3) [59].

\section{Conclusions}

Haplotypes, expression, genetic effects and geographic distribution of wheat yield gene TaGW2 were analyzed.
Major variations occurred at their promoter regions in the three homoeologous genes. Expression levels of TaGW2s were negatively correlated with TKW, which further supported earlier conclusion that the GW2 negatively regulates grain size in cereals. Haplotype interaction analysis exhibited the additive effects between favored haplotypes at TaGW2-6A and TaGW2-6B. We also found that haplotypes at TaGW2-6A and TaGW2-6B underwent strong selection in one century of global wheat breeding. Therefore, there are major genes even though yield is a complex quantitative trait. It illustrated that association based on haplotypes is more effective than single marker in dissection of complex traits. This study provided important genes and functional markers for MAS in wheat yield improvement.

\section{Methods}

\section{Plant materials}

Four hundred and seventy one Chinese wheat accessions including 151 landraces and 320 modern cultivars were used for functional validation of the TaGW2-6B markers (Additional file 9: Table S1), among which 265 accessions (151 landraces and 114 modern cultivars) were mainly from the Chinese wheat mini-core collection (MCC) representing more than $70 \%$ of the genetic diversity of the total Chinese germplasm collection [24]. Association analysis between TaGW2-6A markers and grain traits earlier confirmed that these materials provided good representation and effectiveness when used as a population for association analysis [19,60,61]. In addition, 1,032 introduced wheat cultivars comprising 374 European, 471 American, 51 Australian, 53 CIMMYT and 83 Russian accessions were used for haplotype distribution analysis of TaGW2$6 A$ and $T a G W 2-6 B$ in global wheat cultivars (Additional file 10: Table S2).

Chinese Spring was used to clone the promoter sequences of TaGW2-6B and TaGW2-6D. A set of Chinese Spring (CS) nullisomic-tetrasomic lines was used for chromosome location of TaGW2. Thirty-four accessions with large variations in grain weight, including 22 modern cultivars and 12 landraces (Additional file 1: Table S3), were used for sequencing to detect single-nucleotide polymorphisms (SNPs) and haplotypes in the promoter regions of TaGW2-6B and TaGW2-6D.

A recombinant inbred line (RIL) population derived from Nanda 2419 and Wangshuibai was used for fine mapping of TaGW2-6B.

\section{Measurement of grain weight related traits}

During the 2001-2002 and 2005-2006 wheat-growing seasons, cultivars used in this study were planted at the CAAS-Luoyang Experiment Station in Henan province $\left(111.6^{\circ} \mathrm{E}, 33.8^{\circ} \mathrm{N}\right)$. Each cultivar was planted in $2 \mathrm{~m}$ double rows spaced $25 \mathrm{~cm}$ apart, with 40 seeds planted 
in each row. The field management followed local practices.

After harvest, 20 grains were randomly selected from each genotype and lined up length-wise along a ruler to measure average kernel length (KL), and then arranged breadth-wise to measure kernel width (KW). The middle parts of ten grains were measured with vernier calipers to estimate average kernel thickness (KT). Two independent samples of 500 grains were weighted and the means were converted to one thousand-kernel weight (TKW).

\section{Cloning the promoters of TaGW2-6B and TaGW2-6D}

Genomic DNA was extracted from young leaves of 10day-old seedlings using a modified CTAB method [62]. Primers were designed by the software Primer Premier Version 5.0 (Premier Biosoft International, Palo Alto, CA), and all primers were synthesized by Shanghai Sangon Biological Technology Co., Ltd (http://www.sangon.com/).

Primers pF147 and pR1481 were designed to amplify the $1.5 \mathrm{~kb}$ promoter regions of TaGW2-6B and TaGW2$6 D$ according to the TaGW2-6A promoter sequence. PCR were performed in total volumes of $15 \mu \mathrm{l}$, including 3 pmol of each primer, $120 \mu \mathrm{M}$ of each dNTP, $80 \mathrm{ng}$ genomic DNA, 0.75 unit La-Taq and $7.5 \mu \mathrm{l}$ of $2 \times \mathrm{GC}$ Buffer (TaKaRa Biotechnology (Dalian) Co. Ltd, Product Code: DRR20AG). PCR were performed as follows: $95^{\circ} \mathrm{C}$ for $4 \mathrm{~min}$; followed by 35 cycles of $95^{\circ} \mathrm{C}$ for $30 \mathrm{~s}$, annealing $\left(60-64^{\circ} \mathrm{C}\right)$ for $30 \mathrm{~s}$, and extension at $72^{\circ} \mathrm{C}(30 \mathrm{~s}$ to $3 \mathrm{~min}$ ), and $72^{\circ} \mathrm{C}$ for $30 \mathrm{~s}$, with a final extension of $72^{\circ} \mathrm{C}$ for $10 \mathrm{~min}$. The annealing temperatures and extension times depended on the primer sets and the lengths of the expected PCR products. The PCR products were separated by electrophoresis in agarose gels, and the target bands were extracted and cloned into the pEASY-T1 simple vector and transformed to $\mathrm{DH} 5 \alpha$ competent E. coli cells by the heat shock method (Beijing Trans Gen Biotech Co., Ltd, Product Code: CT111). Positive clones were selected for sequencing by ABI 3730XI DNA Analyzer. To guarantee sequence accuracy, the PCR and DNA sequencing were repeated at least three times.

A Genome Walking Kit (TaKaRa Biotechnology (Dalian) Co. Ltd, Product Code No. 6108) was used to obtain the $5^{\prime}$ flanking promoter sequence of $T a G W 2-6 B$ and TaGW2-6D. The kit was based primarily on the known genomic DNA sequence, utilizing the annealing temperature difference between degenerate primers and specific primers for thermal asymmetric PCR, and flanking sequences were obtained by three nested PCR. Three specific primers TaGW2-SP1, TaGW2-SP2 and TaGW2-SP3 (Additional file 11: Table S4) were designed according to the promoter sequence to amplify the sequences in the unknown regions. Here, TaGW2-SP2 was designed on the inside of TaGW2-SP1, and TaGW2-SP3 was located on the inside of TaGW2-SP2. Each distance between the two primers was $60-100 \mathrm{bp}$. Three PCR were performed in total volumes of $25 \mu \mathrm{l}$, including $80 \mathrm{ng}$ genomic DNA, $4 \mu \mathrm{l}$ of $2.5 \mathrm{mM}$ dNTP mixture, $2.5 \mu \mathrm{l}$ of $10 \times \mathrm{LA}$ PCR Buffer II $\left(\mathrm{Mg}^{2+}\right.$ plus), $1.25 \mathrm{U}$ of TaKaRa LA Taq, $0.5 \mu \mathrm{l}$ of AP Primer $(100 \mathrm{pmol} / \mu \mathrm{l}), 0.5 \mu \mathrm{l}$ of SP Primer $(10 \mathrm{pmol} / \mu \mathrm{l})$. The first PCR was as follows: Taking Chinese Spring DNA as the template, AP Primer as the upstream primer, and TaGW2-SP1 as downstream primer for the first PCR. PCR were performed as follows: $94^{\circ} \mathrm{C}$ for $1 \mathrm{~min}, 98^{\circ} \mathrm{C}$ for $1 \mathrm{~min}$; followed by 5 cycles of $94^{\circ} \mathrm{C}$ for $30 \mathrm{~s}, 62^{\circ} \mathrm{C}$ for $1 \mathrm{~min}, 72^{\circ} \mathrm{C}$ for $2 \mathrm{~min} ; 94^{\circ} \mathrm{C}$ for $30 \mathrm{~s}, 25^{\circ} \mathrm{C}$ for $3 \mathrm{~min}, 72^{\circ} \mathrm{C}$ for $2 \mathrm{~min}$; followed by 15 cycles of $94^{\circ} \mathrm{C}$ for $30 \mathrm{~s}, 62^{\circ} \mathrm{C}$ for $1 \mathrm{~min}, 72^{\circ} \mathrm{C}$ for $2 \mathrm{~min}, 9^{\circ} \mathrm{C}$ for $30 \mathrm{~s}, 62^{\circ} \mathrm{C}$ for $1 \mathrm{~min}, 72^{\circ} \mathrm{C}$ for $2 \mathrm{~min}, 94^{\circ} \mathrm{C}$ for $30 \mathrm{~s}, 44^{\circ} \mathrm{C}$ for $1 \mathrm{~min}, 72^{\circ} \mathrm{C}$ for $2 \mathrm{~min}$; and $72^{\circ} \mathrm{C}$ for $10 \mathrm{~min}$. The second PCR was performed as follows: the first PCR solution was diluted 100 times, taking $1 \mu \mathrm{l}$ as template for the second PCR, AP primer as the upstream, and TaGW2-SP2 as the downstream primer. PCR were performed as follows: 15 cycles of $94^{\circ} \mathrm{C}$ for $30 \mathrm{~s}, 63^{\circ} \mathrm{C}$ for $1 \mathrm{~min}, 72^{\circ} \mathrm{C}$ for $2 \mathrm{~min}, 94^{\circ} \mathrm{C}$ for $30 \mathrm{~s}, 63^{\circ} \mathrm{C}$ for $1 \mathrm{~min}, 72^{\circ} \mathrm{C}$ for $2 \mathrm{~min}, 94^{\circ} \mathrm{C}$ for $30 \mathrm{~s}, 44^{\circ} \mathrm{C}$ for $1 \mathrm{~min}$, $72^{\circ} \mathrm{C}$ for $2 \mathrm{~min}$; and $72^{\circ} \mathrm{C}$ for $10 \mathrm{~min}$. For the third PCR, the second PCR solution was diluted 100 times, then taking $1 \mu \mathrm{l}$ as the template, AP primer as the upstream primer, and TaGW2-SP3 as the downstream primer. PCR were performed as for the second PCR. The three PCR products were separated by electrophoresis in $1 \%$ agarose gels; the target bands were extracted and PCR products were selected for sequencing using the primer TaGW2SP3. A sequence of about 700 bp was obtained by genome walking, taking this sequence as a reference to continue amplifying upstream sequences. Through this method of genome walking, $\sim 2.9 \mathrm{~Kb}$ of promoter sequences of TaGW2-6B and TaGW2-6D were obtained.

\section{SNP identification and functional marker development}

Thirty-four cultivars were initially chosen for detecting sequence variation in the promoter regions of TaGW2-6B and TaGW2-6D. SNPs were identified using DNA Star software (http://www.dnastar.com/). The core elements of the promoters were identified using the TSSP program (http://www.softberry.com). The cis-acting regulatory elements of the promoter were predicted by Plantcare (http://bioinformatics.psb.ugent.be/webtools/plantcare/html/).

Four haplotypes formed by 11 SNPs were found in TaGW2-6B and three markers were developed to distinguish them. Genome-specific primers were designed for these three markers, respectively (Additional file 11: Table S4). Basically, the three systems of PCR and digestion were similar. PCR were performed in total volumes of $15 \mu \mathrm{l}$, including $80 \mathrm{ng}$ genomic DNA, $1.5 \mu \mathrm{l}$ of $10 \times \mathrm{PCR}$ Buffer, $1.5 \mu \mathrm{l}$ of $\mathrm{MgCl}_{2}(25 \mathrm{mM}), 10 \mu \mathrm{M}$ of each primer, 
$0.16 \mu \mathrm{l}$ of dNTP $(25 \mu \mathrm{M}), 0.75 \mathrm{U}$ of Taq (Fermentas). PCR were performed as follows: $95^{\circ} \mathrm{C}$ for $4 \mathrm{~min}$; followed by 35 cycles of $95^{\circ} \mathrm{C}$ for $30 \mathrm{~s}$, annealing $\left(60-64^{\circ} \mathrm{C}\right)$ for $30 \mathrm{~s}$, and extension at $72^{\circ} \mathrm{C}(30-90 \mathrm{~s})$, and $72^{\circ} \mathrm{C}$ for $30 \mathrm{~s}$, with a final extension of $72^{\circ} \mathrm{C}$ for $10 \mathrm{~min}$. The annealing temperatures and extension times depended on the primer sets and the lengths of expected PCR products (Additional file 11: Table S4). Digestions were performed in total volumes of $10 \mu \mathrm{l}$, including $5 \mu \mathrm{l}$ of PCR products, $1 \mu \mathrm{l}$ of $10 \times$ Buffer, $0.1 \mu \mathrm{l}$ of BSA, $0.25 \mu \mathrm{l}$ of restriction enzyme, and $3.65 \mu \mathrm{l}$ of $\mathrm{dd} \mathrm{H}_{2} \mathrm{O}$.

The TaGW2-6B-CAPS marker amplified a $1.4 \mathrm{~Kb}$ genome-specific fragment, which was digested with BstNI (NEB) according to the manufacturer's instructions, and the digested segments were separated on $1.5 \%$ agarose gels with EB. This marker effectively distinguished Hap-6B-1 and three other haplotypes. Hap-6B-1 (no restriction sites) was represented by a single $1.4 \mathrm{~kb}$ band, whereas the other three were digested into $1.0 \mathrm{~Kb}$ and $400 \mathrm{bp}$ bands.

The TaGW2-6B-ACAS marker needs two PCR amplifications, the TaGW2-6B-ACAS-1 primer amplified a 464 bp fragment and the TaGW2-6B-ACAS-2 primer amplified a $626 \mathrm{bp}$ fragment. The two fragments represent Hap-6B-2 and other two haplotypes, respectively; they were easily distinguished in $1.5 \%$ agarose gels.

The TaGW2-6B-dCAPS marker amplified a 263 bp genome-specific fragment; the products were then digested with Hpy166II (NEB) at $65^{\circ} \mathrm{C}$ for $20 \mathrm{~min}$, and the digested segments were separated on $8 \%$ non-denaturing polyacrylamide gels. The marker distinguished Hap-6B-3 (263 bp) and Hap-6B-4 (240 bp).

\section{RNA extraction, reverse transcription and real-time quantitative PCR}

For each cultivar, spikes from all tillers of each individual were tagged at anthesis when the first spikelets on the head flowered, and the date was recorded. Grains were harvested at 5, 10, 15, 20, 25 and 30 days post-flowering (dpf) as well as mature seeds. Genome-specific primers were designed according to cDNA sequence differences of the GW2 homoeologues from chromosomes $6 \mathrm{~A}, 6 \mathrm{~B}$ and $6 \mathrm{D}$ to evaluate the correlation of gene expression levels of TaGW2-6A/6B/6D and grain weight. To investigate the temporal expression profiles of the TaGW2s during grain development, RT-PCR was conducted using developing seeds at $5,10,15,20,25$, and 30 days post-flowering (dpf) and mature seeds from 22 wheat cultivars including 12 small grained and 10 large grained genotypes. mRNA was extracted using TIANGENRNA Plant Plus Reagent. cDNA was synthesized with the SuperScript II System (Invitrogen) according to the manufacturer's instructions. DNA was removed by digestion with DNaseI (Fermentas) before reverse transcription. The expression analysis of TaGW2 was performed with SYBR Premix Ex-Taq
[TaKaRa Biotechnology (Dalian) Co. Ltd, Product Code: DRR041A]. RT-PCR were performed in total volumes of 2 $0 \mu \mathrm{l}$, including $1 \mu \mathrm{L}$ cDNA, $10 \mu \mathrm{l}$ of $2 \times$ SYBR Premix Ex-Taq, $0.4 \mu \mathrm{l}$ of each primer $(10 \mu \mathrm{M})$ and $0.4 \mu \mathrm{l}$ of ROX Reference Dye $(50 \times)$. The primer sets of TaGW2-6A, TaGW2-6B, TaGW2-6D and Actin (Additional file 11: Table S4) were used for amplification of TaGW2 and actin genes, respectively. Three replications were performed to obtain average values and standard deviations of expression level for each gene. Cts were exported and averaged from technical triplicates. Relative expression was determined using the $\Delta C t$ method corrected for primer efficiencies. Actin gene was used as endogenous control, which was not changed too much in different tissues and developmental stages of wheat under our experiment. This housekeeping gene was assayed on our experimental samples and data were normalized to the expression of actin. To compare TaGW2 homoeologous expression, the relative expression values of $T a G W 2 s$ were calculated using the 2- $\Delta \Delta C t$ method [63], with the $5 \mathrm{dpf}$ stage of Chinese Spring as a reference sample for $\Delta \Delta C t$.

\section{Statistical analyses}

Statistical analyses were based on phenotypic data of average grain size and grain weight in two environments. Variance analyses were performed on the SPSS System for Windows version 12.0 to determine phenotypic differences between the four haplotypes individually and in haplotype combinations, based on analysis of variance (One-Way ANOVA) according to Tukey test at the significance level of 5\% $(P \leq 0.05)$. TaGW2-6B was mapped using data from recombinant inbred lines derived from the cross between Nanda 2419 and Wangshuibai using MAPMAKER/EXP 3.0 [64]. Phenotypic explanation rate $\left(R^{2}\right)$ of TaGW2-6A and TaGW2-6B was the ratio between the sum of squares between groups and total squares for the various haplotypes.

\section{Additional files}

\footnotetext{
Additional file 1: Table S3. Wheat accessions used for obtaining of promoter sequences. TKW, One-thousand kernel weight (g), KL, kernel length $(\mathrm{mm}), \mathrm{KW}$, kernel width $(\mathrm{mm}), \mathrm{KT}$, kernel thickness $(\mathrm{mm}) .{ }^{*}$ : accessions used for real-time PCR analysis of TaGW2s.

Additional file 2: Figure S1. Genetic mapping of TaGW2-6B in a Nanda2419 $\times$ Wangshuibai recombinant inbred line (RIL) population. TaGW2-6B gene (red marker) was mapped between Xmag359 and Xwmc341 on chromosome 6B. The left side of the map was map distance/cM, the right side was SSR markers.

Additional file 3: Figure S2. Differences on heading and maturity dates among TaGW2-6B haplotypes in landraces and modern cultivars based on two years of field data. A, Heading dates differences among TaGW2-6B haplotypes in 2002 and 2006. B, Maturity dates differences among TaGW2-6B haplotypes. The bars represent the standard deviation.

Additional file 4: Figure S3. Haplotype frequencies (\%) of TaGW2-6A and TaGW2-6B in wheat cultivars released since the 1950s in China,
} 
Europe and America. $A$, the frequency of Hap- $6 A-A ; B$, the frequency of Hap- $6 A-G ; C$, the frequency of Hap-6B-1; D, the frequency of Hap-6B-4.

Additional file 5: Figure S4. Mean relative expressions of TaGW2-6A $-6 B,-6 D$ in two subgroups. Red lines represent the subgroup with higher TKWs (10 accessions, mean TKW $47.2 \mathrm{~g}$ ) and blue lines represent the subgroup with lower TKWs (12 accessions, mean $28.5 \mathrm{~g}$ ). A, mean relative expressions of TaGW2-6A; B, mean relative expressions of TaGW2-6B; C, mean relative expressions of TaGW2-6D. TaGW2 genes negatively regulate grain size. Normalized values of TaGW2 (relative expression) are given as Mean \pm SD.

Additional file 6: Figure S5. Mean relative expressions of haplotypes in TaGW2-6A at different grain development stages based on 22 wheat accessions. Normalized values of TaGW2 (relative expression) are given as Mean \pm SD.

Additional file 7: Figure S6. TKW and KW for eight haplotype combinations of TaGW2-6A and TaGW2-6B in landraces and modern cultivars grown in two environments. A, TKW for eight haplotype combinations in landraces; B, KW for eight haplotype combinations in landraces; C, TKW for eight haplotype combinations in modern cultivars; D, $\mathrm{KW}$ for eight haplotype combinations in modern cultivars; $A / 1$, Hap-6A-A/ Hap-6B-1; A/2, Hap-6A-A/Hap-6B-2; A/3, Hap-6A-A/Hap-6B-3; A/4, Hap-6A-A/ Нар-6B-4; G/1, Hap-6A-G/Hap-6B-1; G/2, Hap-6A-G/Hap-6B-2; G/3, Hap-6A-G/ Hap-6B-3; G/4, Hap-6A-G/Hap-6B-4.

Additional file 8: Figure S7. Frequencies of TaGW2-6A and TaGW2-6B haplotype combinations in Chinese wheat landraces and modern cultivars.

Additional file 9: Table S1. Accessions used for association analysis and haplotype distribution studies in Chinese wheat collections. L, landraces; M, modern cultivars; TKW, One-thousand kernel weight (g); KL, kernel length $(\mathrm{mm})$; KW, kernel width $(\mathrm{mm})$; KT, kernel thickness $(\mathrm{mm})$; * Chinese mini core collection; I, Northern winter wheat region; Il, Yellow and Huai River valley winter wheat region; III, low and middle Yangtze River valley winter wheat region; IV, southwestern winter wheat region; $V$, southern winter wheat region; $V I$, northeastern spring wheat region; VII, northern spring wheat region; VIII, northwestern spring wheat region; IX, Qinghai-Tibet spring-winter wheat region; X, Xinjiang winter-spring wheat region.

Additional file 10: Table S2. Accessions used for geographic distribution analysis of haplotypes in global wheat cultivars.

Additional file 11: Table S4. Primer sequences used in this study.

\section{Abbreviations}

L: Landraces; M: Modern cultivars; TKW: One-thousand kernel weight (g); $\mathrm{KL}$ : Kernel length (mm); KW: Kernel width (mm); KT: Kernel thickness (mm); MCC: Chinese mini core collection.

\section{Competing interests}

The authors declare that they have no competing interests.

\section{Authors' contributions}

QL carried out the molecular genetic studies, participated in the sequence alignment and drafted the manuscript. HCY participated in the design of the study, performed data analysis and participated in tables and figures. ZXY, MZQ supervised the study and revised the manuscript critically. HJ, WYQ, LT, WLF collected data and measured grain weight related traits. All authors read and approved the final manuscript.

\section{Acknowledgements}

We thank Dr. SL Xue, Nanjing Agricultural University, for help with the fine mapping of the TaGW2-6B gene, and gratefully acknowledge help from Prof. Robert A McIntosh, University of Sydney, with English editing. We are grateful to the China Natural Science Foundation (31270036), Chinese Ministry of Science and Technology (2010CB125902), Ministry of Agriculture (2008ZX08009) and CAAS-Innovation Team Project for supporting this research.

\section{Author details}

${ }^{1}$ Key Laboratory of Crop Gene Resources and Germplasm Enhancment, Ministry of Agriculture/The National Key Facility for Crop Gene Resources and Genetic Improvement/Institute of Crop Science, Chinese Academy of Agricultural Sciences, Beijing 100081, China. ${ }^{2}$ Crop Genomics and Bioinformatics Center and National Key Lab of Crop Genetics and Germplasm Enhancement, Nanjing Agricultural University, Nanjing 210095, Jiangsu, China.

Received: 9 January 2014 Accepted: 8 April 2014

Published: 25 April 2014

\section{References}

1. Varshney RK, Hoisington DA, Tyagi AK: Advances in cereal genomics and applications in crop breeding. Trends Biotechnol 2006, 24:490-499.

2. Gale MD, Devos KM: Comparative genetics in the grasses. Proc Natl Acad Sci U S A 1998, 95:1971-1974.

3. Yu J, Hu S, Hu SN, Wang J, Li SG, Liu B, Deng YJ, Dai L, Zhou Y, Zhang X, Cao M, Liu J, Sun J, Tang J, Chen Y, Huang X, Lin W, Ye C, Tong W, Cong L, Geng J, Han Y, Li L, Li W, Hu G, Huang X, Li W, Li J, Liu Z, Li L, et al: A draft sequence of the rice genome (Oryza sativa L. ssp. indica). Science 2002, 296(5565):79-92.

4. Goff SA, Ricke D, Lan TH, Presting G, Wang R, Dunn M, Glazebrook J, Sessions A, Oeller P, Varma H, Hadley D, Hutchison D, Martin C, Katagiri F, Lange BM, Moughamer T, Xia Y, Budworth P, Zhong J, Miguel T, Paszkowski U, Zhang S, Colbert M, Sun WL, Chen L, Cooper B, Park S, Wood TC, Mao L, Quail P, et al: A draft sequence of the rice genome (Oryza sativa L. ssp. japonica). Science 2002, 296(5565):92-100.

5. Xing YZ, Zhang QF: Genetic and molecular bases of rice yield. Annu Rev Plant Biol 2010, 61:421-442.

6. Bai XF, Wu B, Xing YZ: Yield-related QTLs and their applications in rice genetic improvement. J Integr Plant Biol 2012, 54(5):300-311.

7. Fan CC, Xing YZ, Mao HL, Lu TT, Han B, Xu CG, Li XH, Zhang QF: GS3, a major QTL for grain length and weight and minor QTL for grain width and thickness in rice, encodes a putative transmembrane protein. Theor Appl Genet 2006, 112:1164-1171.

8. Song XJ, Huang W, Shi M, Zhu MZ, Lin HQ: A QTL for rice grain width and weight III encodes a previously unknown RING-type E3 ubiquitin ligase. Nat Genet 2007, 39:623-630.

9. Weng JF, Gu SH, Wan XY, Gao H, Guo T, Su N, Lei CL, Zhang X, Cheng ZJ, Guo XP, Wang JL, Jiang L, Zhai HQ, Wan JM: Isolation and initial characterization of GW5, a major QTL associated with rice kernel width and weight. Cell Res 2008, 18:1199-1209.

10. Wang SK, Wu K, Yuan QB, Liu XY, Liu ZB, Lin XY, Zeng RZ, Zhu HT, Dong GJ, Qian Q, Zhang GQ, Fu XD: Control of grain size, shape and quality by OsSPL16 in rice. Nat Genet 2012, 44(8):950-954.

11. Ishimaru K, Hirotsu N, Madoka Y, Murakami N, Hara N, Onodera H, Kashiwagi T, Ujiie K, Shimizu B, Onishi A, Miyagawa H, Katoh E: Loss of function of the IAA-glucose hydrolase gene TGW6 enhances rice grain weight and increases yield. Nat Genet 2013, 45(6):707-711.

12. Xue WY, Xing YZ, Weng XY, Zhao Y, Tang WJ, Wang L, Zhou HJ, Yu SB, Xu CG, Li XH, Zhang QF: Natural variation in Ghd7 is an important regulator of heading date and yield potential in rice. Nat Genet 2008, 40:761-767.

13. Wang ET, Wang JJ, Zhu XD, Hao W, Wang LY, Li Q, Zhang LX, He W, Lu BR, Lin HX, Ma H, Zhang GQ, He ZH: Control of rice kernel filling and yield by a gene with a potential signature of domestication. Nat Genet 2008, 40:1370-1374.

14. Brenchley R, Spannagl M, Pfeifer M, Barker GL, D'Amore R, Allen AM, McKenzie N, Kramer M, Kerhornou A, Bolser D, Kay S, Waite D, Trick M, Bancroft I, Gu Y, Huo N, Luo MC, Sehgal S, Gill B, Kianian S, Anderson O, Kersey P, Dvorak J, McCombie WR, Hall A, Mayer KF, Edwards KJ, Bevan MW, Hall N: Analysis of the bread wheat genome using whole-genome shotgun sequencing. Nature 2012, 491(7426):705-710.

15. Jia JZ, Zhao SC, Kong XY, Li YR, Zhao GY, He WM, Appels RD, Pfeifer M Tao Y, Zhang X, Jing R, Zhang C, Ma Y, Gao L, Gao C, Spannagl M, Mayer KF, Li D, Pan S, Zheng F, Hu Q, Xia X, Li J, Liang Q, Chen J, Wicker T, Gou C, Kuang $H, H e G$, Luo Y, et al: Aegilops tauschii draft genome sequence reveals a gene repertoire for wheat adaptation. Nature 2013, 496:91-95.

16. Ling HQ, Zhao SC, Liu DC, Wang LY, Sun H, Zhang C, Fan HJ, Li D, Dong LL, Tao Y, Gao C, Wu H, Li Y, Cui Y, Guo X, Zheng S, Wang B, Yu K, Liang Q, Yang W, Lou X, Chen J, Feng M, Jian J, Zhang X, Luo G, Jiang Y, Liu J, Wang 
$Z$, Sha Y, et al: Draft genome of the wheat A-genome progenitor Triticum urartu. Nature 2013, 496:87-90.

17. Luo MC, Gu YQ, You FM, Deal KR, Ma YQ, Hu YQ, Huo NX, Wang $Y$, Wang J, Chen S, Jorgensen CM, Zhang Y, McGuire PE, Pasternak S, Stein JC, Ware D, Kramer M, McCombie WR, Kianian SF, Martis MM, Mayer KF, Sehgal SK, Li W, Gill BS, Bevan MW, Simková H, Dolezel J, Weining S, Lazo GR, Anderson OD, et al: A 4-gigabase physical map unlocks the structure and evolution of the complex genome of Aegilops tauschii, the wheat D-genome progenitor. Proc Natl Acad SC U S A 2013, 110:7940-7945.

18. Li Q, Li L, Yang XH, Warburton ML, Bai GH, Dai JR, Li JS, Yan JB: Relationship, evolutionary fate and function of two maize co-orthologs of rice GW2 associated with kernel size and weight. BMC Plant Biol 2010, 10:143.

19. Su ZQ, Hao CY, Wang LF, Dong YC, Zhang XY: Identification and development of a functional marker of TaGW2 associated with grain weight in bread wheat (Triticum aestivum L.). Theor Appl Genet 2011, 122(1):211-223.

20. Zhang XY, Chen JS, Shi CL, Chen JN, Zheng FF, Tian JC: Function of TaGW2-6A and its effect on grain weight in wheat (Triticum aestivum L.). Euphytica 2013, 192:347-357.

21. Yang ZB, Bai ZY, Li XL, Wang P, Wu QX, Yang L, Li LQ, Li XJ: SNP identification and allelic-specific PCR markers development for TaGW2, a gene linked to wheat kernel weight. Theor Appl Genet 2012, 125(5):1057-1068.

22. Bednarek J, Boulaflous A, Girousse C, Ravel C, Tassy C, Barret P, Bouzidi MF, Mouzeyar S: Down-regulation of the TaGW2 gene by RNA interference results in decreased grain size and weight in wheat. J Exp Bot 2012, 63(16):5945-5955.

23. Somers DJ, Isaac $P$, Edwards $K$ : A high density microsatellite consensus map for bread wheat (Triticum aestivum L.). Theor Appl Genet 2004, 109:1105-1114.

24. Hao CY, Dong YC, Wang LY, You GX, Zhang HN, Ge HM, Jia JZ, Zhang XY: Genetic diversity and construction of core collection in Chinese wheat genetic resources. Chin Sci Bull 2008, 53:1518-1526.

25. Zhang XY, Li CW, Wang LF, Wang HM, You GX, Dong YS: An estimation of the minimum number of SSR alleles needed to reveal genetic relationships in wheat cultivars I. Information from large-scale planted cultivars and cornerstone breeding parents in Chinese wheat improvement and production. Theor Appl Genet 2002, 106:112-117.

26. Pritchard JK: Deconstructing maize population structure. Nat Genet 2001, 28:203-204.

27. Zhuang QS: Chinese Wheat Improvement and Pedigree Analysis. Beijing: Agricultural Press; 2003 (in Chinese).

28. Davierwala AP, Reddy AP, Lagu MD, Ranjekar PK, Gupta VS: Marker assisted selection of bacterial blight resistance genes in rice. Biochem Genet 2001, 39(7-8):261-278

29. Koebner RM, Summers RW: 21st century wheat breeding, plot selection or plate detection? Trends Biotechnol 2003, 21:59-63.

30. Zhou PH, Tan YF, He YQ, Xu CG, Zhang Q: Simultaneous improvement for four quality traits of Zhenshan 97 , an elite parent of hybrid rice, by molecular marker-assisted selection. Theor Appl Genet 2003, 106(2):326-331.

31. Chen XW, Li SG, Ma YQ, Li HY, Zhou KD, Zhu LH: Marker-assisted selection and pyramiding for three blast resistance genes, $P i-d(t) 1$ Pi-b, Pi-ta2, in rice (in Chinese with English abstract). Chin J Biotechnol 2004, 20(5):708-714.

32. He GM, Sun CQ, Fu YC, Fu Q, Zhao KJ, Wang CL, Zhang Q, Ling ZZ, Wang XK: Pyramiding of senescence inhibition IPT gene and Xa23 for resistance to bacterial blight in rice (Oryza sativa L.). Acta Genet Sin 2004, 31(8):836-841.

33. Joseph M, Gopalakrishnan S, Sharma RK, Singh VP, Singh AK, Singh NK, Mohapatra T: Combining bacterial blight resistance and basmati quality characteristics by phenotypic and molecular marker-assisted selection in rice. Mol Breed 2004, 13(4):377-387.

34. Sharma PN, Torii A, Takumi S, Mori N, Nakamura C: Marker-assisted pyramiding of brown planthopper (Nilaparvata lugens Stål) resistance genes Bph1 and Bph2 on rice chromosome 12. Hereditas 2004, 140(1):61-69

35. Yi G, Lee SK, Hong YK, Cho YC, Nam MH, Kim SC, Han SS, Wang GL, Hahn TR, Ronald PC, Jeon JS: Use of Pi5(t) markers in marker-assisted selection to screen for cultivars with resistance to Magnaporthe grisea. Theor Appl Genet 2004, 109(5):978-985.

36. Tan CX, Ji XM, Yang Y, Pan XY, Zuo SM, Zhang YF, Zou JH, Chen ZX, Zhu LH, Pan XB: Identification and marker-assisted selection of two major quantitative genes controlling rice sheath blight resistance in backcross generations. Acta Genet Sin 2005, 32(4):399-405.

37. Wang YH, Liu SJ, Ji SL, Zhang WW, Wang CM, Jiang L, Wan JM: Fine mapping and marker-assisted selection (MAS) of a low glutelin content gene in rice. Cell Res 2005, 15(8):622-630.

38. Liu QQ, Li QF, Cai XL, Wang HM, Tang SZ, Yu HX, Wang ZY, Gu MH: Molecular marker-assisted selection for improved cooking and eating quality of two elite parents of hybrid rice. Crop Sci 2006, 46:2354-2360

39. Miyata M, Yamamoto T, Komori T, Nitta N: Marker-assisted selection and evaluation of the QTL for stigma exsertion under japonica rice genetic background. Theor Appl Genet 2007, 114(3):539-548.

40. Liu YN, He ZH, Appels R, Xia XC: Functional markers in wheat, current status and future prospects. Theor Appl Genet 2012, 125:1-10.

41. Jiang QY, Hou J, Hao CY, Wang LF, Ge HM, Dong YC, Zhang XY: The wheat (T. aestivum) sucrose synthase 2 gene (TaSus2) active in endosperm development is associated with yield traits. Funct Integr Genom 2011, 11:49-61.

42. Ma DY, Yan J, He ZH, Wu L, Xia XC: Characterization of a cell wall invertase gene TaCwi-A1 on common wheat chromosome $2 \mathrm{~A}$ and development of functional markers. Mol Breed 2012, 29:43-52.

43. Han LM, Yang FP, Xia XC, Yan J, Zhang Y, Qu YY, Wang ZW, He ZH: Distribution of genes related to plant height, kernel weight and disease resistance among wheat cultivars from major countries (in Chinese with English abstract). J Triticeae Crops 2011, 31:824-831.

44. Li YB, Fan CC, Xing YZ, Jiang YH, Luo LJ, Sun L, Shao D, Xu CJ, Li XH, Xiao $J H, H e Y Q$, Zhang QF: Natural variation in GS5 plays an important role in regulating grain size and yield in rice. Nat Genet 2011, 43:1266-1269.

45. Li Q, Yang XH, Bai GH, Warburton ML, Mahuku G, Gore M, Dai JR, Li JS, Yan JB: Cloning and characterization of a putative GS3 ortholog involved in maize kernel development. Theor Appl Genet 2010, 120:753-763.

46. Hou J, Jiang QY, Hao CY, Wang YQ, Zhang HN, Zhang XY: Global selection on sucrose synthase haplotypes during a century of wheat breeding. Plant Physiol 2014, 164(4):1918-1929.

47. Liu YN, Xia XC, He ZH: Characterization of dense and erect panicle 1 gene (TaDep1) located on common wheat group 5 chromosomes and development of allele-specific markers (in Chinese with English abstract). Acta Agron Sin 2013, 39:589-598.

48. Wang LF, Balfourier F, Hao CY, Exbrayat-Vinson F, Dong YC, Ge HM, Zhang XY: Comparison of genetic diversity level between European and East-Asian wheat collections using SSR markers (in Chinese with English abstract). Sci Agric Sin 2007, 40:2667-2678

49. Wright SI, Vroh BI, Schroeder SG, Yamasaki M, Doebley JF, McMullen MD, Gaut BS: The effects of artificial selection on the maize genome. Science 2004, 308:1310-1314

50. Olsen KM, Purugganan MD: Molecular evidence on the origin and evolution of glutinous rice. Genetics 2002, 162:941-950.

51. Peng J, Richards DE, Hartley NM, Murphy GP, Devos KM, Flintham JE, Beales J, Fish LJ, Worland AJ, Pelica F, Sudhakar D, Christou P, Snape JW, Gale MD, Harberd NP: 'Green revolution' genes encode mutant gibberellin response modulators. Nature 1999, 400:256-261.

52. Frary A, Nesbitt TC, Grandillo S, Knaap E, Cong B, Liu J, Meller J, Elber R, Alpert KB, Tanksley SD: fw2.2: a quantitative trait locus key to the evolution of tomato fruit size. Science 2000, 289(5476):85-88.

53. Fay JC, Wu Cl: Hitchhiking under positive Darwinian selection. Genetics 2000, 155:1405-1413.

54. Zhang XY, Tong YP, You GX, Hao CY, Ge HM, Wang LF, Li B, Dong YC, Li ZS: Hitchhiking effect mapping, a new approach for discovering agronomic important genes. Agric Sci China 2007, 6:255-264.

55. Barrero R, Bellgard M, Zhang XY: Diverse approaches to achieving grain yield in wheat. Funct Integr Genom 2011, 11:37-48.

56. Shomura A, Izawa T, Ebana K, Ebitani T, Kanegae H, Konishi S, Yano M: Deletion in a gene associated with grain size increased yields during rice domestication. Nat Genet 2008, 40(8):1023-1028.

57. Hao CY, Wang LF, Ge HM, Dong YC, Zhang XY: Genetic diversity and linkage disequilibrium in Chinese bread wheat (Triticum aestivum L.) revealed by SSR markers. PLoS One 2011, 6(2):e17279. 10.1371/journal. pone.0017279. 
58. Cavanagha CR, Chao S, Wang SC, Huang BE, Stephen S, Kiani S, Forrest K Saintenac C, Brown-Guedira GL, Akhunova A, See D, Bai G, Pumphrey M, Tomar L, Wong D, Kong S, Reynolds M, da Silva ML, Bockelman H, Talbert L, Anderson JA, Dreisigacker S, Baenziger S, Carter A, Korzun V, Morrell PL, Dubcovsky J, Morell MK, Sorrells ME, Hayden MJ, et al:

Genome-wide comparative diversity uncovers multiple targets of selection for improvement in hexaploid wheat landraces and cultivars. Proc Natl Acad Sci U S A 2013, 110:8057-8062.

59. Heun M, Schäfer-Pregl R, Klawan D, Castagna R, Accerbi M, Borghi B, Salamini F: Site of einkorn wheat domestication identified by DNA fingerprinting. Science 1997, 278:1312-1314.

60. Wang LF, Ge HM, Hao CY, Dong YC, Zhang XY: Identifying loci influencing 1,000-kernel weight in wheat by microsatellite screening for evidence of selection during breeding. PLOS One 2012, 7(2):e29432.

61. Zhang DL, Hao CY, Wang LF, Zhang XY: Identifying loci influencing grain number by microsatellite screening in bread wheat (Triticum aestivum L.). Planta 2012, 236:1507-1517.

62. Chen DH, Ronald PC: A rapid DNA minipreparation method suitable for AFLP and other PCR applications. Plant Mol Biol Report 1999, 17:53-57.

63. Livak KJ, Schmittgen TD: Analysis of relative gene expression data using real-time quantitative PCR and the $2^{-\triangle \Delta C T}$ method. Methods 2001, 25:402-408.

64. Lander ES, Botstein D: Mapping Mendelian factors underlying quantitative traits using RFLP linkage maps. Genetics 1989, 21:185-199. genetic effects and geographic distribution of the wheat yield gene TaGW2. BMC Plant Biology 2014 14:107.

\section{Submit your next manuscript to BioMed Central and take full advantage of:}

- Convenient online submission

- Thorough peer review

- No space constraints or color figure charges

- Immediate publication on acceptance

- Inclusion in PubMed, CAS, Scopus and Google Scholar

- Research which is freely available for redistribution 